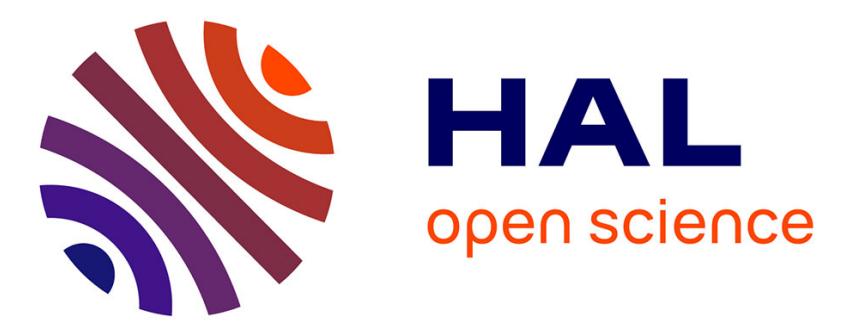

\title{
Assessment of ground motion variability and its effects on seismic hazard analysis: A case study for Iceland
}

Teraphan Ornthammarath, John Douglas, Ragnar Sigbjörnsson, Carlo G. Lai

\section{To cite this version:}

Teraphan Ornthammarath, John Douglas, Ragnar Sigbjörnsson, Carlo G. Lai. Assessment of ground motion variability and its effects on seismic hazard analysis: A case study for Iceland. Bulletin of Earthquake Engineering, 2011, 9 (4), pp.931-953. 10.1007/s10518-011-9251-9 . hal-00567864

\section{HAL Id: hal-00567864 https: / hal-brgm.archives-ouvertes.fr/hal-00567864}

Submitted on 22 Feb 2011

HAL is a multi-disciplinary open access archive for the deposit and dissemination of scientific research documents, whether they are published or not. The documents may come from teaching and research institutions in France or abroad, or from public or private research centers.
L'archive ouverte pluridisciplinaire HAL, est destinée au dépôt et à la diffusion de documents scientifiques de niveau recherche, publiés ou non, émanant des établissements d'enseignement et de recherche français ou étrangers, des laboratoires publics ou privés. 


\title{
Assessment of Ground Motion Variability and Its Effects on Seismic Hazard Analysis: A Case Study for Iceland
}

\author{
Teraphan Ornthammarath $^{1,2}$, John Douglas ${ }^{2,3}$, Ragnar Sigbjörnsson ${ }^{2,4}$, Carlo Giovanni \\ $\mathrm{Lai}^{5,6}$ \\ ${ }^{1}$ ROSE School, IUSS Pavia, Italy \\ ${ }^{2}$ Earthquake Engineering Research Centre, University of Iceland, Iceland \\ ${ }^{3}$ RNSC/RIS, BRGM, 3 avenue C. Guillemin, BP 36009, 45060 ORLEANS Cedex 2, France \\ ${ }^{4}$ Department of Structural Engineering, Norwegian University of Science and Technology (NTNU), \\ Trondheim, Norway \\ ${ }^{5}$ European Centre for Training and Research in Earthquake Engineering (EUCENTRE), Pavia, Italy \\ ${ }^{6}$ Department of Structural Mechanics, University of Pavia, Italy
}

(E-mail:teraphan@rimes.int)

\begin{abstract}
Probabilistic seismic hazard analysis (PSHA) generally relies on the basic assumption that ground motion prediction equations (GMPEs) developed for other similar tectonic regions can be adopted in the considered area. This implies that observed ground motion and its variability at considered sites could be modelled by the selected GMPEs. Until now ground-motion variability has been taken into account in PSHA by integrating over the standard deviation reported in GMPEs, which significantly affects estimated ground motions, especially at very low probabilities of exceedance. To provide insight on this issue, ground-motion variability in the South Iceland Seismic Zone (SISZ), where many ground-motion records are available, is assessed. Three statistical methods are applied to separate the aleatory variability into source (inter-event), site (inter-site) and residual (intra-event and intra-site) components. Furthermore, the current PSHA procedure that makes the ergodic assumption of equality between spatially and temporal variability is examined. In contrast to the ergodic assumption, several recent studies show that the observed ground-motion variability at an individual location is lower than that implied by the standard deviation of a GMPE. This could imply a mishandling of aleatory uncertainty in PSHA by ignoring spatial variability and by mixing aleatory and epistemic uncertainties in the computation of sigma. Station correction coefficients are introduced in order to capture site effects at different stations. The introduction of the non-ergodic assumption in PSHA leads to larger epistemic uncertainty, although this is not the same as traditional epistemic uncertainty modelled using different GMPEs. The epistemic uncertainty due to the site correction coefficients (i.e. mean residuals) could be better constrained for future events if more information regarding the characteristics of these seismic sources and path dependence could be obtained.
\end{abstract}


Keywords: Seismic hazard analysis, GMPEs, Analysis of variance (ANOVA), Two-way-fit plot, Single-station sigma

\section{Introduction}

In recent years, much research attention has been directed into better understanding and constraining aleatory variability, commonly called sigma $(\sigma)$, due to its impacts on calculated ground-motion values especially at very low annual rates of exceedance. Because in hazard analysis the variability in predicted ground-motion is modelled as a Gaussian distribution, hazard estimates do not saturate but grow indefinitely with decreasing annual rates of exceedance. In such cases, the hazard is driven by the tails of lognormal distribution of the residual rather than any physical basis. The proposed solutions by either truncating on the amplitude of the ground motion or on a chosen epsilon value (e.g. 3 or 4) are still considered to be too subjective and difficult to justify (Strasser et al., 2008), despite the belief that the physical limits of earthquake ground motions could be defined (e.g. Andrews et al., 2007). Moreover, the dropping of sigma in hazard analysis does not only lead to underestimating the computed ground-motion intensity but it is also inconsistent with the probabilistic approach (Bommer and Abrahamson, 2006). The more viable approach of better understanding sigma and sources of uncertainty is the aim of much recent research.

Historically, sigma values have not changed greatly through time even with larger strong-motion databanks and more complicated functional forms of GMPEs (e.g. Strasser et al., 2009). Most published GMPEs report sigmas for PGA around 0.30 in terms of common (base 10) logarithms. Most GMPEs consider a constant aleatory variability with respect to magnitude and distance (sigma weakly depends on structural period). However, there are some published GMPEs reporting a variation of sigma with magnitude, ground-motion amplitude, and/or distance, (e.g. Midorikawa and Ohtake 2004; Ambraseys et al. 2005; Abrahamson and Silva 2008; Chiou and Youngs, 2008). The aleatory variability also changes according to different definitions of the horizontal component of motion (e.g. the geometric mean or a single arbitrary component). The latter definition has larger variability than the former since it takes into account the variability between the two orthogonal horizontal components. The parameter compatibility among different GMPEs for adjusting both the median value and its associated aleatory variability has been addressed by Beyer and Bommer (2006) and Boore et al. (2006). Scherbaum et al. (2006) discussed the effects of systematically and rigorously applying the laws of uncertainty propagation to all of the required conversion and adjustments, which results in large aleatory variabilities, and its effects on the PSHA of the PEGASOS project. They concluded that priorities should be given to develop suites of GMPEs that employ the same parameter definitions (e.g. source-to-site distance definitions and horizontal component definitions).

Joyner and Boore (1981) first separated the aleatory variability into inter- and intra-event components by using a two-stage regression technique. Fukushima and Tanaka (1990) showed that failing 
to separate these components in typical multiple regression leads to an underestimation of the magnitude and distance dependency in GMPEs. Moreover, since there are differences in the numbers of records-perevent, the larger number of records from one particular event may bias the estimated coefficients during the regression process. Inter-event variability is observed in the variations between ground motions of different earthquakes with the same magnitude and style-of-faulting due to differences such as a higher stress drop, slip direction and slip velocity and it could be considered as event variability. On the other hand, intraevent variability may be thought of as a spatial variability which is observed for a given earthquake at sites with the same geotechnical classification and at the same distance from the source. Some proposed factors that could influence the level of ground motion beyond a simple soil and rock classification are nearsurface shear wave velocity (e.g. $\mathrm{V}_{\mathrm{S} 30}$ ), depth to basement, weak-motion amplification, attenuation in the near surface, nonlinear site response, and also wave propagation effects. The inter- and intra-event residuals are generally assumed to be independent, and the total standard deviation is computed by the square root of the sum of the squares of the inter- and intra-event standard deviations.

In empirical GMPEs, the inter-event variability is generally lower than the intra-event variability (Table 1). However, some studies (e.g. Lee et al., 1998; Douglas and Gehl, 2008) suggest that the interevent variability is higher at short periods than at long periods. Lee et al. (1998) explain this effect by observing that at high frequencies the amplitudes of ground motion are much more sensitive to focusing, defocusing, or other source heterogeneous process, while, at longer periods, the geological structure is dominant for long-period waves. Also at very long periods ground-motion amplitudes should be completely controlled by seismic moment (which is modelled in GMPEs by magnitude). Moreover, differences in stress drop has a strong impact on ground motion at high frequencies (e.g. Brune, 1970).

Joyner and Boore (1993) further subdivided the intra-event term into an inter-site and a record-torecord component by using a one-stage maximum likelihood regression procedure. In addition to regression analysis, various techniques have also been proposed in the literature over the past couple of decades to decompose the aleatory variability into the three different components previously mentioned, e.g. analysis of variance (ANOVA) and two-way-fit plots. These procedures, however, have not been regularly applied to the GMPEs adopted for PSHA studies for various reasons (e.g. unavailable or limited ground-motion records). Better insight into the source of aleatory variability could be useful in improving current GMPEs and eventually PSHA results.

This study is carried out by exploiting the strong-motion dataset available from moderate earthquakes (Mw 5.0-6.5) in the South Iceland Seismic Zone (SISZ) that have occurred in the past decade or so. To this purpose various techniques are applied here to these recordings. The material presented in this article is presented in more detail in Ornthammarath (2010).

In traditional PSHA, GMPEs are adopted to estimate ground motion based on the assumption of equality between spatially and temporal variability, which is generally referred to as the ergodic assumption (Anderson and Brune, 1999). In other words, the predicted median ground motion and its variability at a given distance are assumed to be identical irrespective of the location. Recently there are sufficient ground- 
motion records from a single station to test this traditional hypothesis. In contrast to the ergodic assumption, several recent studies have shown that the observed ground-motion variability at an individual location is lower than that implied by the standard deviation of a GMPE (e.g. Chen and Tsai, 2002; Atkinson, 2006; Morikawa et al., 2008). These studies also assess the variability of earthquake ground motion based on the computed sigma for each station, commonly known as single-station sigma. They report a reduction in sigma of 10 to $40 \%$ by considering a single station and 40 to $70 \%$ for a single path and station (Atkinson, 2006; Morikawa et al., 2008). This could imply a mishandling of aleatory uncertainty in PSHA by ignoring spatial variability and by mixing aleatory and epistemic uncertainties in the computation of sigma, which could lead to unrealistic ground motions from PSHA especially at long return periods (e.g. Strasser et al., 2009). However, to assess spatial variability data from dense seismic networks, recordings from different earthquake scenarios should be used. In this study, the ground-motion variability at individual stations is assessed based on well-constrained GMPEs. Subsequently the impact of applying the traditional and non-ergodic assumption on the assessed seismic hazard based is compared using the SISZ as an example.

\section{Icelandic strong-motion data}

Iceland is located on the Mid-Atlantic Ridge, the border between the Eurasian Plate and the North American Plate. Crossing the island, the ridge is shifted eastward through two major fracture zones, one in the South, the SISZ, and another in the North, the so-called Tjörnes Fracture Zone (TFZ), which extends far offshore. The size of earthquakes within these zones may reach magnitude seven or more (Sigbjörnsson et al., 2004). Significant earthquakes outside these areas are often attributed to volcanic activity or geothermal processes. However, these types of earthquakes do not generally produce significant effects on engineering structures.

Established in 1984, the Icelandic Strong-Motion Network is operated by the Earthquake Engineering Research Centre of the University of Iceland. At present, the databank contains over 3300 time-series recorded in earthquakes with moment magnitudes $\left(\mathrm{M}_{\mathrm{w}}\right)$ ranging from 2.0 to 6.5 and epicentral distances ranging from close to zero up to roughly $350 \mathrm{~km}$. Some important recorded events include the South Iceland earthquakes in June 2000 and the Olfus earthquake in May 2008. See Sigbjörnsson et al. (2004) for more details.

\section{Assessment of ground-motion variability}

In following sections, ground-motion variability in the SISZ is assessed and compared using different approaches. Lastly, the robustness of the ANOVA approach is evaluated based on the number of available ground-motion records. 


\subsection{Functional form and regression analysis}

Data from the Icelandic Strong-Motion Network, compiled in the European Strong-Motion Database (Ambraseys et al., 2004), were used in this study. The selected strong ground motion data include records from six strike-slip earthquakes with Mw>5 (Figure 1 and Table 2), which were recorded by 31 different stations in the SISZ (note that not all of these stations were triggered in the six earthquakes). In total, 81 records were selected for the analysis from the 31 stations (28 and 3 stations for rock and stiff soil site classes, respectively).

Only high-quality data were chosen following visual inspection. The recording stations were classified according to the average shear-wave velocity over the uppermost $30 \mathrm{~m}$ at the site $\left(\mathrm{V}_{\mathrm{S} 30}\right)$, with those having $\mathrm{V}_{\mathrm{S} 30}$ above $750 \mathrm{~m} / \mathrm{s}$ being classified as rock, and those with values between $360 \mathrm{~m} / \mathrm{s}$ and $750 \mathrm{~m} / \mathrm{s}$ as stiff soil. However, since none of the stations have measured shear-wave velocity profiles, descriptions of the local site conditions were used to assess the site classification. Out of 81 records, 68 records are from rock and 13 are from stiff soil sites. The majority of earthquakes in the SISZ, and all earthquakes considered here, have strike-slip mechanisms since it is a transform zone. Hence the ground-motion models considered here are for strike-slip faulting. The adopted functional form for the derived GMPE is:

$$
\log y=b_{1}+b_{2} M w+b_{3} \log \left(\sqrt{R_{j b}^{2}+b_{4}^{2}}\right)+b_{5} S_{S}+\varepsilon_{e}+\varepsilon_{s}+\varepsilon_{r}
$$

where $y$ is the PGA or 5\% damped spectral acceleration (SA) considering the geometric mean horizontal components; $b_{1}, b_{2}, b_{3}, b_{4}$, and $b_{5}$ are the coefficients obtained by regression analysis; $M_{w}$ is the moment magnitude; and $R_{j b}$ is the Joyner-Boore distance (the distance to the surface projection of the causative fault in $\mathrm{km}$ ). For $M_{w}<6.0$ the epicentral distance, $R_{e p i}$, is used instead since the causative faults cannot be well constrained. $S_{S}$ is a dummy variable taking a value of 1 for stiff soil and 0 for rock sites. The error term is decomposed into three components: inter-event $\left(\varepsilon_{e}\right)$, inter-station $\left(\varepsilon_{s}\right)$, and record-to-record $\left(\varepsilon_{r}\right)$ components respectively, which are assumed to be independent zero-mean normal random variables with variances

$\sigma_{e}^{2}, \sigma_{s}^{2}$, and $\sigma_{r}^{2}$ respectively. The total variance of $\log y$ can computed as the sum of the three variances.

Magnitude-dependent decay is now widely accepted and modelled since the spectral acceleration of ground motions from large earthquake decays at a slower rate with distance than those from small earthquakes (e.g. Ambraseys et al., 2005; Cotton et al., 2008). However, the narrow magnitude range considered here (i.e. $5.1 \leq \mathrm{M}_{\mathrm{w}} \leq 6.5$ ) does not allow magnitude dependency of the decay to be determined, and magnitude-independent decay is thus assumed. In addition, an anelastic attenuation term was dropped since the resulting anelastic constant was positive, indicating that the dataset is not sufficient to consider geometric and anelastic attenuation separately even though the frequency dependence of the geometric spreading rate could be taken as evidence of a frequency-dependent anelastic term. 
To investigate magnitude saturation, a quadratic term in magnitude was added. However, there were insufficient data to constrain the coefficient and, therefore, this term was also dropped. The one-stage maximum-likelihood regression method of Chen and Tsai (2002) was then applied. Chen and Tsai (2002) found that their regression technique yielded the same coefficients as that of the one-stage maximum likelihood and the random-effects regression techniques developed by Joyner and Boore (1993) and Brillinger and Preisler (1984) respectively. As in previous studies (e.g. Sigbjörnsson et al., 2009), we observed that strong ground motion in Iceland attenuates rapidly with distance and the $b_{3}$ values, which are sometimes assumed to be -1 based on simple theory of geometric attenuation, are found to be lower at longer periods (Table 3). $b_{2}$ is found to increase with increasing period, as it is generally observed.

From Table 4 , for periods up to $0.5 \mathrm{~s}$, the inter-station variability is larger than the inter-event variability while the dominant component of variance is the record-to-record component. This observation shows that, for short periods aleatory variability of GMPEs for Iceland could be lowered by better site characterization. However, for longer periods $(T \geq 1 \mathrm{~s})$, the inter-event and inter-station variability contribute roughly equally to the total variability. Record-to-record variability remains the largest component.

The computed sigma is generally lower than that generally reported for other well constrained models. The sigmas decrease with increasing period, which is in contrast to what is generally observed (e.g. Ambraseys et al., 2005; Akkar and Bommer, 2010). This might be due to using data from only six earthquakes, three of which (accounting for $60 \%$ of the records) have $\mathrm{M}_{\mathrm{W}}$ between 6.3 and 6.5 , and all of which are strike-slip events. In addition, the data are from a small geographical area and from a restricted set of stations (e.g. nine stations recorded five earthquakes). Another possible explanation for low standard deviations at long periods could be the geology of Iceland, where there are no deep alluvium soil deposits unlike in other parts of Europe or California and, hence, basin and valley effects are limited.

\subsection{Analysis of variance (ANOVA)}

In addition to regression, ANOVA has also been performed to determine the source of variability in this dataset and to conduct significance tests. This procedure was first developed by Fisher (1918). Douglas and Gehl (2008) apply such a method to separate the contribution of site and source effects to the overall variability in earthquake ground motions, with respect to a given GMPE.

The analysis employs the residuals, calculated for each station and each earthquake, with respect to a GMPE. Subsequently, the sums of squares for total, site, earthquake, and record-to-record variances are computed. The variance of earthquake, site, and record-to-record components are then derived. For the details of the procedure see Douglas and Gehl (2008). The ratios of inter- event and inter-site variances to residual variance ( $\mathrm{R}_{\mathrm{E}}$ and $\mathrm{R}_{\mathrm{S}}$ respectively) [see, e.g., Eq. 13 and 14 in Douglas and Gehl (2008)] are computed to indicate the significance of unmodelled source and site effects. Since, for ANOVA the complete matrix of records per station and per event is required, only a subset of the data used for the 
regression analysis can be used. This subset consists of five earthquakes recorded by nine stations (45 records in total) (Table 5).

Table 6 presents the ratios of inter-and intra-events variances to residual variance obtain by using our local Icelandic, two European and three NGA GMPEs. The results from the local Icelandic GMPE show that unmodelled site effects are particularly important at low structural periods (i.e. $\mathrm{T} \leq 0.5 \mathrm{~s}$ ). However, at longer periods, both source and site effects are equally significant, in accordance with the standard deviation reported in Table 4. For European and NGA GMPEs, Akkar and Bommer (2010), hereinafter called AB10, Ambraseys et al. (2005), hereinafter called ADSS05, Campbell and Bozorgnia (2008), hereinafter called CB08, Boore and Atkinson (2008), hereinafter called BA08, and Chiou and Youngs (2008), hereinafter called CY08, give contradictory results, which show larger non-modelled source effects for all periods. The different results obtained from European and NGA GMPEs compared to the Icelandic GMPE are possibly due to peculiarities of the Icelandic tectonic setting, where strong motion attenuates rapidly. Inappropriate regression coefficients of the selected European and NGA GMPEs that control the slope of distance attenuation are possibly the cause of this apparent unmodelled source effect. This indicates a limitation of the Douglas and Gehl (2008) approach: if the selected GMPEs do not correctly model the magnitude and distance dependence of the data then the results are not reliable.

Two-way-fit plots, as introduced by Tukey (1972) and used in Douglas and Gehl (2008), are shown in Figure 2. The computed average residuals with respect to earthquakes (descending lines) and stations (ascending lines) can be read from the y-axis [for graph construction details refer to Douglas and Gehl (2008)]. Since these lines represent the variance of source and site effects, the wider the spread of the earthquake or station lines the greater the importance of unmodelled source and site effects in the underlying GMPE. From Figure 2, it can be observed that the station lines are more widely separated than those of the earthquakes. This indicates the large variation in non-modelled site effects at short periods. Both residual lines become narrower at longer periods (Figure 2), which implies that both earthquake and site effects are equally important at long periods. The dominance of source and site variances at short and long periods, respectively, is similar to that previously reported in Table 4.

In addition, Lee et al. (1998)'s method is implemented to further confirm the previously computed results from ANOVA. Lee et al (1998)'s method considers stations that recorded more than one earthquake. The residuals are corrected for the inter-event variance and pairs of records belonging to the same station are randomly combined and plotted. A good correlation between pairs is expected and the residual versus residual plot will follow a diagonal line if site effects are the dominant factor. However, if site effects are perfectly represented in the regression, the resulting scatter plot will show statistically uncorrelated points.

Figure $3 \mathrm{a}$ ) and b) show the residuals of SA at 0.2 and $2 \mathrm{~s}$ for different combinations of stations. The residuals of SA at $0.2 \mathrm{~s}$ mainly lie along the diagonal with a correlation coefficient of 0.32 , but the residuals of SA at $2 \mathrm{~s}$ do not follow the diagonal and the correlation coefficient is only 0.11 , indicating that site effects are less significant than that for SA at $0.2 \mathrm{~s}$. This is in agreement with the previous calculations obtained from both regression and ANOVA procedures. 


\subsection{Robustness of ANOVA}

The robustness of the ANOVA method in partitioning the ground-motion variability into source and site effect with respect to available data can be evaluated by using sets of simulated PGAs and SAs of various sizes (Table 7) with known components of variability. The assumed components of variability are shown Table 8, in which the site effect contributes to larger variability than source effects and it is assumed that they are independent zero-mean normal random variables. Moreover, to ensure that the computed results are statistical significant, 1000 simulated datasets for each different size of dataset were generated. In Table 7 differences in ratios of residuals describing intra- and inter-event variance to residual variance (i.e. RS RE) [see Eq. 13 and 14 of Douglas and Gehl (2008)] are shown. A negative residual means that the ANOVA method could not predict the true component of variability because of insufficient data to separate the components of variability. It can be clearly observed that the larger the dataset the better the ability of the ANOVA method to partition the variability into source and site effects.

\section{Seismic hazard assessment without the ergodic assumption}

In this section, ground-motion variability at individual stations is assessed based on well-constrained GMPEs. Subsequently, the impact of applying the traditional and non-ergodic assumption on the assessed seismic hazard is compared for a group of sites in the SISZ.

\subsection{Single-station sigma}

The non-ergodic assumption implies that the estimation of ground motion and its variability should depend on the spatial variability of ground motion due to site and path effects. This is in contrast to traditional PSHA where ground-motion variability at every location is assumed uniform. For any individual site, where strong-motion records have been observed from multiple earthquakes, the average of single-station sigmas is usually less than the sigma from the whole dataset from multiple sites used in regression analysis (e.g. Atkinson, 2006). The traditional multiple-station sigma includes contributions to the variability from different paths and sites. In fact, the uncertainty in path and site effects should be treated as epistemic uncertainties for recurrent events in small areas (Anderson and Brune, 1999). Moreover, in order to move away from the ergodic assumption, once the single-station sigma has been estimated, the median ground motion must also be adjusted according to the average residual for each station. For example, considering Figure 4, in a traditional GMPE the median ground motions for different stations are assessed by averaging residuals, which then results in shifting the median residual of each individual site as well as its corresponding variability (generally modelled assuming the lognormal distribution), thereby requiring a 
broader distribution to cover the whole dataset. The aleatory variability (i.e. sigma) should be transferred to epistemic uncertainty (i.e. mean residual of each individual station). However, a drawback of the nonergodic assumption is that it requires sufficient data to validate this hypothesis and records from all possible earthquake scenarios at the considered sites in order to better constrain median ground motion and its variability at these sites.

The determination of single-station sigma requires the analysis of residuals between observed and predicted values for each individual station, for which standard deviations should be determined separately. The study area is the SISZ (Figure 5) where a number of large and moderate earthquakes have occurred in the last century. The $1912 \mathrm{M}_{\mathrm{S}} 7.05$ earthquake is so far the largest instrumentally-recorded earthquake in the SISZ. From the Icelandic strong-motion database, data has been selected based on the availability of records from nine stations and five earthquakes with magnitudes larger than $5.0\left(\mathrm{M}_{\mathrm{W}}\right)$ (45 records in total) with source-to-site distances less than $100 \mathrm{~km}$ (Table 5 and Figure 5). Four records from the $\mathrm{M}_{\mathrm{W}} 6.3$ event in 2008 (i.e. Hella, Reykjavik Foldaskoli, Reykjavik-Heidmork, and Selfoss hospital at 36, 41, 38, and 8 $\mathrm{km}$ Joyner-Boore distance, respectively) were also included to expand dataset in this analysis. This dataset is not sufficient to study single-site and single-path sigma.

Average log residuals and its standard deviation for each station [single-station sigma (Atkinson, 2006)] based on the AB10 GMPEs were computed. Figure 6 shows the variability in the residuals for each station and the average residual for PGA and SA at 0.2, 0.5, 1.0, and 2.0s. Table 9 and Table 10 tabulate the average residual and single-station sigma, respectively. The average residual is applied as a site correction coefficient for each considered station and structural period thus:

$$
\log y_{i}^{*}(T)=\log y(T)+S_{i}(T)
$$

where $y$ is the predicted ground motion from the traditional GMPE, $S_{i}$ is the site correction coefficient for the $i^{\text {th }}$ station at a considered period (T) and $y_{i}{ }^{*}$ is the corrected predicted ground motion for each individual site. The standard error of the mean $\left(\sigma_{\mu}\right)$ is also computed:

$$
\sigma_{\mu}=\frac{\sigma_{i}}{\sqrt{N_{i}}}
$$

where $N_{i}$ is the number of records from the station $i$ and $\sigma_{i}$ is the standard deviation of the residual for station $i$. One can also derive an expression for standard error of the standard deviation $\left(\sigma_{\sigma}\right)$ that is valid for large $N_{i}$ as:

$$
\sigma_{\sigma}=\frac{\sigma_{i}}{\sqrt{2 N_{i}}} .
$$

The weighted-average single station sigma has been computed for all considered periods and for all nine considered stations as: 


$$
\sigma(T)=\frac{\sum_{i=1}^{9} \sigma_{i} N_{i}}{\sum_{i=1}^{9} N_{i}} .
$$

From Table 9, the average residuals relative to AB10 are presented along with the standard errors of their means. For rock stations, the average residuals are all overestimated by AB10. The three stations in Reykjavik, and the stations at Burfell and Irafoss Power Plants give lower average residuals than those of Selfoss Hospital and Hveragerdi Church. For shallow soil stations, the average residuals of Kaldarholt indicate larger soil amplification than at Hella, which is consistent with the results previously observed using the local GMPEs.

Overall, the single-station sigmas derived using AB10 indicate lower variability than the multi-site sigmas particularly at long structural periods (Table 11). The reduction in sigma when comparing singlesite to multi-site sigmas is observed to be 13 to $16 \%$ at short periods, similar to that reported by Atkinson (2006). The trend of decreasing sigma with increasing period can also be observed as a typical characteristic of strong ground motion in Iceland, in contrast to the original multi-site sigma of AB10. The confidence interval of the mean is still considerably high, showing that the inclusion of more records to constrain the dependence of sigma on path and source could be helpful in characterising this epistemic uncertainty (e.g. Anderson, 2006; Morikawa et al, 2008). The analysis was repeated using three NGA GMPEs (Boore and Atkinson, 2008; Chiou and Youngs, 2008; Campbell and Bozorgnia, 2008). However, the computed single-station sigmas were larger than those reported for the original models. This could be partly because the current Icelandic dataset is too small to estimate the variability relative to these models, or that these NGA models are not appropriate for the current study area.

The residuals after introducing the station coefficients to the AB10 equations are examined as a function of magnitude and distance for short and long periods (Figure 7 to 10). It is clearly observed that before applying the station coefficients, the residuals with respect to $\mathrm{AB} 10$ are negative (i.e. overestimation of ground motion in the SISZ), which is expected given the faster attenuation of short period ground motion compared to most active areas in Europe. The station-correction coefficients for both periods lead to better behaved residuals as a function of magnitude and distance. The bias is reduced from -0.27 before the introduction of station coefficients to almost zero for PGA. However, there is still a noticeable negative bias (i.e. overestimation) for magnitudes below 6 and positive bias (i.e. underestimation) for magnitudes larger than 6, which is due to the magnitude scaling of the AB10 equation. Nevertheless, it should be to noted that the ground-motion database of the present study is still too small to prove the hypothesis of different magnitude scaling, and the reported station coefficients should be considered preliminary until new information becomes available. For long periods (Figure 9 and 10) the introduction of station coefficients reduces the scatter in the residuals with respect to both magnitude and distance, and the bias is reduced from -0.07 to almost zero. The reduction of scatter after introducing station coefficients is greater for short periods than at long periods. 


\subsection{Application of single-station sigma in PSHA}

Following the determination of site correction and single-station sigma for each individual site, PSHA is performed for a group of sites in the SISZ using the delineated source zone (Figure 5). Three stations in the SISZ (Selfoss hospital, Hveragerdi church, and Kaldarholt) were selected as case studies because their locations inside the seismic source zone means that differences in source-to-site distances from all potential earthquake sources would not be significant. In the truncated Gutenberg-Richter model for the SISZ, the minimum earthquake magnitude is set equal to 5.0 because smaller earthquakes are judged not likely to cause damage to engineered structures. The maximum (upper bound) magnitude is set equal to 7.5 to account for large earthquakes that have been observed in this zone. Shallow strike-slip faulting mechanism with an average focal depth of $10 \mathrm{~km}$ (Table 2) dominates the earthquake catalogue in the current study area. This characteristic can sometimes be observed by surface fault rupture. Consequently the depth of considered seismogenic zone is fixed at $10 \mathrm{~km}$. For comparison between PSHA computed using the traditional and non-ergodic approaches, a set of seismic hazard curves for PGA are computed using CRISIS 2007 version 1.1 (Ordaz et al., 2007) using the previously described seismic zone and its associated Gutenberg-Richter magnitude frequency model (Table 12).

Figure 11 shows the hazard curves using only AB10 for a rock site for Selfoss Hospital. The local GMPE (Section 3) has not been employed since the considered maximum magnitude in the current PSHA is well beyond its applicability range (i.e. 5.0 $<\mathrm{M}_{\mathrm{W}}<6.5$ ). The NGA equations were also dropped since they do not seem to be appropriate for the study area. Introducing the station correction and the singlestation sigma (e.g. 0.257 for PGA) compared to that from regression model of Akkar and Bommer (2010) (e.g. 0.279 for PGA) reveals a considerable reduction in estimated ground motion at long return periods from that obtained using the traditional approach. The epistemic uncertainty in the site correction coefficient, in contrast to traditional epistemic uncertainty based on different GMPEs, has been considered by introducing this site coefficient with its standard deviation. This results in fractiles of the hazard curves. At 475-year return period, the non-ergodic assumption gives estimated PGAs for the 16th and 84th percentile intervals of 0.21 and $0.34 \mathrm{~g}$ respectively, while the traditional approach gives $0.46 \mathrm{~g}$. Whereas at 2475-year return period, the estimated PGA using the single-station sigma ranges from 0.33 to $0.56 \mathrm{~g}$, the traditional approach gives $0.77 \mathrm{~g}$. The reduction of estimated ground motion at 475 - and 2475 -year return period is between $-26 \%$ and $-54 \%$.

The use of the non-ergodic assumption by introducing the single-station sigma and a site correction coefficient increases epistemic uncertainty at a selected return period but reduces the aleatory variability. Although the disadvantage of non-ergodic assumption is that it increases epistemic uncertainty, it indicates a practical approach to further constrain this epistemic uncertainty by gathering more data to better define the hazard related to a specific seismic source and path dependence (Morikawa et al., 2008; 
Wang and Takada 2009; Atkinson, 2011), which is not considered here due to scarcity of available strongmotion data.

From the traditional approach, the estimated ground motion at Hveragerdi Church, 10-km from Selfoss hospital, is identical for both 475 - and 2475 -year return periods, 0.46 and $0.78 \mathrm{~g}$, respectively (due to their proximity and location within the single source zone). However, after introducing site correction and single-station sigma, PSHA using the non-ergodic assumption leads to PGA at a 475-year return period in the range 0.27 to $0.42 \mathrm{~g}$, i.e. a reduction of the estimated ground motion of between -10 and $-40 \%$. For 2475-year return period, the estimated PGA is in the range $0.40 \mathrm{~g}$ to $0.64 \mathrm{~g}$, i.e. a reduction of estimated ground motion between -18 and $-48 \%$ (Figure 12). It is worthwhile noting that the reduction of estimated ground motion by introducing the non-ergodic assumption at Hveragerdi Church is lower than that at Selfoss Hospital. This might be due to a presence of geothermal vents in this town that could amplify the site response (Halldorsson and Sigbjörnsson, 2009).

Although the introduction of the non-ergodic assumption does reduce the estimated ground motion at specific return periods (e.g. 475-year return period), for some stations where site effects lead to larger than average ground motion, the predicted intensity at these stations using the proposed single-station sigma and site correction may not always lead to a reduction in the estimated ground motion. For example, at Kaldarholt station (Figure 13) the estimated ground motion at 475 -year return period using the nonergodic assumption (between 0.39 to $0.47 \mathrm{~g}$ ) and the traditional approach $(0.45 \mathrm{~g})$ give comparable values. The change at 475 -year return period is between $+5 \%$ (i.e. increase) and $-14 \%$ (i.e. decrease), and the reduction at 2475 -year return period is from -18 to $-28 \%$. At very long return periods, however, the impact of separating aleatory variability from epistemic uncertainty reduces the estimated ground motion. Since the computed single-station sigma for Kaldarholt station is very low (i.e. 0.109 in $\log 10$ scale), the computed hazard curve becomes a straight line.

It is interesting to mention that the percentage of reduction of estimated ground motion increases with increasing return period, and for a site with a strong local site effect or a position close to a known fault (resulting in larger than average ground motion), the degree of reduction of estimated ground motion is greater than that of other sites with lower than average but more variable ground motions (i.e. Kaldarholt, Hveragerdi Church, and Selfoss Hospital, accordingly). This can be explained by the fact that the ergodic assumption uniformly spreads aleatory variability to all computed sites resulting in overestimated ground motion at stations with less observable site effects and which are not located close to faults.

Beauval et al. (2008) presents a procedure for using strong-motion observations from a station with a long operating interval to check the results of PSHA. The empirical recurrence curve for PGA is derived resulting in the cumulative occurrence rates versus PGA (i.e. the hazard curve). The uncertainty on the observed rates is taken into account by using the coefficient of variation $(\mathrm{COV})$ :

$$
\operatorname{COV}(\lambda)=\frac{1}{\sqrt{N}}
$$


where $N$ is the number of events considered. The higher the number of events considered, the lower the uncertainty on the estimated rate. Beauval et al. (2008) estimates occurrence rates from observed ground motion at an accuracy of $30 \%$ for low acceleration levels (i.e. $0.0001-0.001 \mathrm{~g}$ for a French station and $0.1 \mathrm{~g}$ for stations in high seismicity regions in Greece and California). In the present study, the estimation of occurrence rate to the same accuracy from the three stations in SISZ is found to be in the range of 0.01$0.03 \mathrm{~g}$. This type of test, through comparing observations and the hazard curves at a site, still remains out of reach for return periods that are usually of interest for seismic design (e.g. 475 years and above).

\section{Conclusions}

This study investigated the variability of Icelandic earthquake ground motions and separated it into site and source effects by using the techniques proposed by Chen and Tsai (2002), Douglas and Gehl (2008) and Lee et al. (1998). The Icelandic strong ground motion database in the SISZ with data from six earthquakes with magnitudes larger than 5 from 31 different stations ( 81 strong-motion records in total) has been used to investigate the source of the variability. In order to explore the inter-event and inter-station variability, local empirical GMPEs for PGA and 5\% damped SA considering the geometric mean of the two horizontal components at 0.2, 0.5, 1.0, and 2.0s were developed. Because of limited data, magnitude-dependent geometric spreading and magnitude saturation terms could not be implemented. Regressions were performed using the one-stage maximum-likelihood regression procedure developed by Chen and Tsai (2002), with the intention of separating the inter-event and inter-station components of variance.

The ANOVA procedure of Douglas and Gehl (2008) along with the techniques of Lee et al. (1998) and Chen and Tsai (2002) lead to a similar conclusion that the site effect is particularly important at shorter periods and source and site effects are equally important at longer periods (i.e. $\mathrm{T} \geq 1 \mathrm{~s}$ ). This conclusion is also reached by Bindi et al. (2009) using Italian data. This finding that unmodelled site effects are the dominant contributor to short-period ground-motion variability suggests that it is necessary to better characterize site conditions in the SISZ. Moreover, two-way-fit plots also clearly indicate the variability among different stations and earthquakes.

The application of other well-constrained GMPEs in the SISZ has also been investigated following the same procedure; however, the results are different to those obtained using the local GMPEs. For both European and NGA GMPEs the inter-event variance is the largest contributor to the total variability at most considered periods. This conclusion could partially be ascribed to the use of GMPEs that do not correctly model the magnitude and distance dependence of the investigated data, e.g. see Scasserra et al. (2009) as an example of this for Italy.

Examination of ground-motion variability and its effect on PSHA has been examined by using Icelandic strong-motion records. An analysis of residuals was performed to define and constrain mean residual and single-station sigma. This analysis suggests that current PSHA procedures that use the aleatory variability directly from published GMPEs can overestimate the observed variability. Based on the Akkar 
and Bommer (2010) GMPE, a reduction in observed variability of around 10\% at short periods and around $50 \%$ at long periods is observed (Table 11). The degree of variability in residuals after introducing station corrections also decreases, particularly at short periods, in agreement with results shown in Section 3 where site effects lead to larger variability at short periods than at long periods (Figure 2 and Table 4).

In addition, single-station sigma and the mean residuals have been employed in PSHA for three different stations in a uniform source zone for the SISZ. The results were compared to those from the traditional PSHA procedure. The introduction of the non-ergodic assumption in PSHA leads to larger epistemic uncertainty, though it is not the same as traditional epistemic uncertainty that is modelled using different GMPEs. The epistemic uncertainty due to the site correction coefficient (i.e. mean residual) could be well constrained for future events if more information regarding the characteristics of these seismic sources and their path dependency (e.g. near-fault directivity term and azimuthal variability) could be obtained. The aleatory component could then be considered as a specific scenario characteristic (e.g. an asperity in earthquake source) (Morikawa et al., 2008). This observed aleatory variability is generally smaller than that suggested by regression models which are usually adopted in traditional PSHA and can lead to non-physically high predicted ground motions at long return periods. In this way, the large epistemic uncertainty and low aleatory variability would be informative when the previously-mentioned information becomes available and the design ground motions could be selected based on specific contributions from different earthquake scenarios.

Finally, the difference in estimated ground motion in making the ergodic or non-ergodic assumptions were observed to be in the range $+5 \%$ (increase) to $-54 \%$ (decrease) at 475 -year return periods depending on the site. The degree of reduction increases with increasing return period. This can be explained by the effect of combining aleatory variability and epistemic uncertainty together resulting in overestimating predicted ground motions at a site with less obvious site effects or a site located far from faults. The results of traditional PSHA at return periods regularly employed in seismic design (e.g. 475 years) would then be overestimated for a site with generally smaller than average ground motion and it would be comparable at a site where, in general, average ground motion is higher.

\section{Acknowledgements}

This study was partly supported by the University of Iceland Research Funds. The first author would like to acknowledge ROSE School - IUSS (Institute for Advanced Study) of Pavia, Italy for the financial support. Dr John Douglas thanks Landsvirkjun and the University of Iceland for his visiting professorship at the Earthquake Engineering Research Centre. The authors acknowledge Dr Gail Atkinson and an anonymous reviewer for their careful reviews of the article. 


\section{References}

Abrahamson, N. A., Silva, W. J., (2008) Summary of the Abrahamson \& Silva NGA ground motion relations, Earthquake Spectra, 24, 67-97

Akkar, S. and Bommer, J.J. (2010) Empirical Equations for the Prediction of PGA, PGV and Spectral Accelerations in Europe, the Mediterranean Region and the Middle East, Seismological Research Letters 81:2, 195-206.

Ambraseys, N.N., Smit, P., Douglas J, Margaris B, Sigbjornsson R, Olafsson S, Suhadolc P, Costa G (2004) Internet-Site for European Strong-Motion Data, Bollettino di Geofisica Teorica ed Applicata 45:3,113-129.

Ambraseys NN, Douglas J, Sarma SK, Smit PM (2005) Equations for the estimation of strong ground motions from shallow crustal earthquakes using data from Europe and the Middle East: horizontal peak ground acceleration and spectral acceleration. Bulletin of Earthquake Engineering 3:1, 1-53. doi:10.1007/s10518-005-0183-0

Anderson, J. G., Brune, J. N. (1999) Probabilistic seismic hazard analysis without the ergodic assumption. Seismological Research Letters, 70:1, 19-28.

Andrews, D. J., Hanks, T. C., Whitney, J. W. (2007) Physical limits on ground motion at Yucca Mountain. Bulletin of the Seismological Society of America, 97:6, 1771-1792.

Atkinson, G. M. (2006). Single-station sigma. Bulletin of the Seismological Society of America, 96:2, 446455.

Atkinson, G.M. (2011) An empirical perspective on uncertainty in earthquake ground motion prediction, Canadian. Journal of Civil Engineering (In press)

Beauval, C., Bard, P.-Y., Hainzl, S., Guegun, P. (2008) Can strong-motion observations be used to constrain probabilistic seismic hazard estimates?. Bulletin of the Seismological Society of America, 98:2, $509-520$

Beyer K, Bommer JJ (2006) Relationships between median values and between aleatory variabilities for diferent defnitions of the horizontal component of motion. Bulletin of the Seismological Society of America, 96: 4A, 1512-1522. 
Bindi D, Luzi L, Pacor F (2009) Interevent and Interstation Variability Computed for the Italian Accelerometric Archive (ITACA). Bulletin of the Seismological Society of America, 99, 4, 2471-2488

Bommer, J.J. and Abrahamson, N.A. (2006) Why Do Modern Probabilistic Seismic-Hazard Analyses Often Lead to Increased Hazard Estimates? Bulletin of the Seismological Society of America, 96:6, 1967-1977

Boore, D. M., Watson-Lamprey, J.,Abrahamson, N.A. (2006) Orientation-independent measures of ground motion. Bulletin of the Seismological Society of America. 96, 1502--1511.

Boore, D.M. and Atkinson, G.M. (2008) Ground-motion prediction equations for the average horizontal component of PGA, PGV, and 5\%-damped PSA at spectral periods between $0.01 \mathrm{~s}$ and $10.0 \mathrm{~s}$, Earthquake Spectra, 24, 99-138.

Brillinger, D.R. and Preisler, H.K. (1984). An exploratory analysis of the Joyner-Boore attenuation data Bulletin of the Seismological Society of America. 74, 4, 1441- 1450.

Brune (1970) Tectonic Stress and the Spectra of Seismic Shear Waves from Earthquakes. Journal of Geophysical Research, 75,26, 4997-5009, doi:10.1029/JB075i026p04997

Campbell, K.W. and Bozorgnia, Y. (2008). NGA ground motion model for the geometric mean horizontal component of PGA, PGV, PGD and 5\% damped linear elastic response spectra for periods ranging from 0.01 to10 s, Earthqake Spectra, 24, 139-172.

Chen, Y-H and Tsai, C-C P (2002) A New Method for estimation of the Attenuation Relationship with Variance Components, Bulletin of the Seismological Society of America, 92:5, 1984-1991

Chiou, B.S.J. and Youngs, R.R. (2008). Chiou-Youngs NGA ground motion relations for the geometric mean horizontal component of peak and spectral ground motion parameters, Earthquake Spectra, 24, 173216.

Cotton F, Pousse G, Bonilla F, Scherbaum F (2008) On the Discrepancy of Recent European GroundMotion Observations and Predictions from Empirical Models: Analysis of KiK-net Accelerometric Data and Point-Sources Stochastic Simulations Bulletin of the Seismological Society of America, 98:5, 22442261 
Douglas J, Gehl P (2008) Investigating strong ground-motion variability using analysis of variance and two-way-fit plots Bulletin of Earthquake Engineering , 6:3, 389-405

Fisher RA (1918) The correlation between relatives on the supposition of Mendelian inheritance, Transactions of the Royal Society of Edinburgh. 52, 399-433.

Fukushima, Y. and Tanaka, T. (1990) A new attenuation relation for peak horizontal acceleration of strong earthquake ground motion in Japan, Bulletin of the Seismological Society of America, 80, 757-783.

Halldorsson, B., Sigbjörnsson, R. (2009) The Mw 6.3 Ölfus earthquake at 15:45 UTC on 29 May 2008 in South Iceland: ICEARRAY strong-motion recordings, Soil Dynamics and Earthquake Engineering., 29, 1073-1083.

Joyner, W.B. and Boore, D.M. (1981) Peak horizontal acceleration and velocity from strong-motion records including records from the 1979 Imperial Valley, California, earthquake. Bulletin of the Seismological Society of America,. 71:6, 2011-2038

Joyner, W.B. and Boore, D.M. (1993). Methods for regression analysis of strong-motion data, Bulletin of the Seismological Society of America, 83, 469-487.

Lee, Y, Zeng, Y, and Anderson, J G (1998) A simple strategy to examine the sources of errors in attenuation relations Bulletin of the Seismological Society of America. 88:1, 291-296.

Midorikawa S, Ohtake Y (2004). "Variance of peak horizontal acceleration and velocity in attenuation relationships," Proc. of the 13th World Conference on Earthquake Engineering August 1-6, 2004,Vancouver, B.C., Canada. Paper No. 3361.

Morikawa, N., Kanno, T., Narita, A., Fujiwara, H., Okumura, T., Fukushima, Y., Guerpinar, A. (2008). "Strong motion uncertainty determined from observed records by dense networks in Japan," Journal of Seismology, 12:4, 529-546. doi: 10.1007/s10950-008-9106-2.

Ordaz, M., Aguilar, A., Arboleda, J. (2007) CRISIS 2007 Ver 1.1 Program for computing Seismic Hazard. Universidad Nacional Autónoma de México (UNAM)

Ornthammarath, T. (2010) Influence of hazard modeling methods and the uncertainty of GMPEs on the results of probabilistic seismic hazard analyses. PhD Dissertation, ROSE school, IUSS Pavia, Italy. 
Scasserra, G., Stewart, J.P., Bazzurro, P., Lanzo, G., and Mollaioli, F. A Comparison of NGA groundmotion prediction equations to Italian data. Bulletin of the Seismological Society of America, 99:5, 29612978.

Scherbaum, F., J. J. Bommer, F. Cotton, H. Bungum, and F. Sabetta. (2006) Ground-Motion Prediction in PSHA: A Post-PEGASOS Perspective. Paper presented at the First European Conference on Earthquake Engineering and Seismology, Geneva, Switzerland

Sigbjörnsson R, Ólafsson S, Thórarinsson Ó (2004) Strong-motion recordings in Iceland. In Proceedings of the13th World Conference on Earthquake Engineering. Vancouver: Mira, Paper no. 2370.

Sigbjörnsson, R., Snæbjörnsson, J., Higgins, S., Halldórsson, B. (2009) A note on the Mw 6.3 earthquake in Iceland on 29 May 2008 at 15:45 UTC. Bulletin of Earthquake Engineering, 7, 113-126. doi:10.1007/s10518-008-9087-0

Stafford, P.J., Strasser, F.O., and Bommer, J.J. (2008) An evaluation of the applicability of the NGA models to ground-motion prediction in the Euro-Mediterranean region Bulletin of Earthquake Engineering, $6,149-177$

Strasser, F.O., Bommer, J.J., Abrahamson, N.A. (2008) Truncation of the distribution of ground-motion residuals, Journal of seismology 12:1, 79-105.

Strasser, F.O., Abrahmson, N.A., Bommer, J.J. (2009) Sigma: Issues, insights, and challenges, Seismological Research Letters 80,40-56.

Tukey, J.W. (1972) Some graphic and semigraphic displays. In: Bancroft TA (ed) Statistical Papers in Honor of George W. Snedecor, The Iowa State University Press, Ames, Iowa, USA, 293-316

Wang, M. and Takada, T. (2009) A Bayesian framework for prediction of seismic ground motion Bulletin of the Seismological Society of America, 99:4, 2348-2364.

Table 1. Comparison of intra-and inter-event variability for different GMPEs and periods; for Boore and Atkinson (2008) (BA08), for Ambraseys et al (2005) (ADSS05) and Akkar and Bommer (2010) (AB10) $\sigma$ in $\log 10(\mathrm{y})$

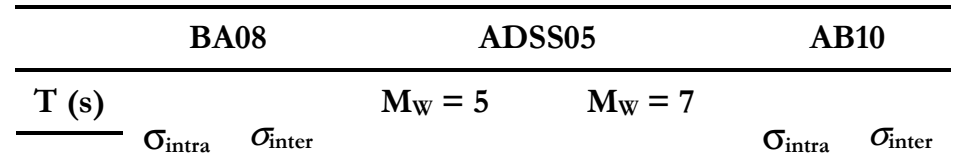




\begin{tabular}{|c|c|c|c|c|c|c|c|c|}
\hline & & & $\sigma_{\text {intra }}$ & $\sigma_{\text {inter }}$ & $\sigma_{\text {intra }}$ & $\sigma_{\text {inter }}$ & & \\
\hline PGA & 0.22 & 0.11 & 0.34 & 0.11 & 0.21 & 0.07 & 0.26 & 0.10 \\
\hline 0.2 & 0.23 & 0.13 & 0.38 & 0.12 & 0.22 & 0.07 & 0.28 & 0.11 \\
\hline 0.5 & 0.24 & 0.12 & 0.40 & 0.13 & 0.25 & 0.08 & 0.31 & 0.12 \\
\hline 1.0 & 0.25 & 0.13 & 0.31 & 0.12 & 0.31 & 0.12 & 0.29 & 0.15 \\
\hline 2.0 & 0.25 & 0.17 & 0.28 & 0.13 & 0.28 & 0.13 & 0.28 & 0.17 \\
\hline
\end{tabular}

Table 2. Earthquakes and strong-motion data used in this study

\begin{tabular}{cccccccc}
\hline \multicolumn{2}{c}{ Date / Time (UTC) } & Name & Latitude & Longitude & $\begin{array}{c}\text { Depth } \\
\text { (km) }\end{array}$ & Rec \# & $\boldsymbol{M}_{\boldsymbol{w}}$ \\
\hline 4 June 1998 & $21: 36: 54$ & Mt. Hengill Area & 64.04 & -21.29 & 10 & 10 & 5.4 \\
13 November 1998 & $10: 38: 34$ & Oelfus & 63.95 & -21.35 & 10 & 10 & 5.1 \\
17 June 2000 & $15: 40: 41$ & South Iceland & 63.97 & -20.36 & 15 & 17 & 6.5 \\
17 June 2000 & $15: 42: 51$ & South Iceland AF & 63.97 & -20.63 & 11 & 9 & 5.8 \\
21 June 2000 & $0: 51: 48$ & South Iceland AF & 63.97 & -20.71 & 10 & 18 & 6.4 \\
29 May 2008 & $15: 45: 59$ & Olfus & 63.92 & -21.17 & 12 & 17 & 6.3 \\
\hline
\end{tabular}

Table 3. Regression coefficients for SA $\left(\mathrm{m} / \mathrm{s}^{2}\right)$ for the geometric mean of the two horizontal components.

\begin{tabular}{cccccc}
\hline $\mathbf{T}$ (s) & $\mathbf{b 1}$ & $\mathbf{b} 2$ & $\mathbf{b 3}$ & $\mathbf{b} 4$ & $\mathbf{b 5}$ \\
\hline 0.0 & -2.622 & 0.643 & -1.249 & 3.190 & 0.344 \\
0.2 & -2.505 & 0.634 & -1.075 & 1.946 & 0.403 \\
0.5 & -3.129 & 0.761 & -1.297 & 2.438 & 0.186 \\
1.0 & -3.522 & 0.773 & -1.202 & 3.579 & 0.083 \\
2.0 & -5.149 & 0.971 & -1.114 & 4.730 & 0.042 \\
\hline
\end{tabular}

Table 4. Inter-event, inter-station, record-to-record, and the total standard deviation for the geometric mean of the two horizontal components

\begin{tabular}{cccccccc}
\hline $\mathbf{T}(\mathbf{s})$ & $\boldsymbol{\sigma}_{\text {event }}$ & $\boldsymbol{\sigma}_{\text {station }}$ & $\boldsymbol{\sigma}_{\text {record }}$ & $\boldsymbol{\sigma}$ & $\boldsymbol{\sigma}_{\text {event }}^{2} / \boldsymbol{\sigma} \mathbf{2}$ & $\boldsymbol{\sigma}_{\text {station }}^{2} / \boldsymbol{\sigma}^{2}$ & $\boldsymbol{\sigma}_{\text {record }} / \boldsymbol{\sigma}^{2}$ \\
\hline 0.0 & 0.0723 & 0.1198 & 0.1640 & 0.2156 & 0.11 & 0.31 & 0.58 \\
0.2 & 0.0757 & 0.1405 & 0.1761 & 0.2377 & 0.10 & 0.35 & 0.55 \\
0.5 & 0.0765 & 0.1244 & 0.1276 & 0.1939 & 0.16 & 0.41 & 0.43 \\
1.0 & 0.1138 & 0.0930 & 0.1610 & 0.2180 & 0.27 & 0.18 & 0.55 \\
2.0 & 0.0882 & 0.0712 & 0.1224 & 0.1668 & 0.28 & 0.18 & 0.54 \\
\hline
\end{tabular}

Table 5. Records used for ANOVA and two-way-fit plots. (1): Free field, (2): Structure-related free field.

\begin{tabular}{ccccccc}
\hline EID & A & B & C & D & E \\
& Date (DD/MM/YY) & $04 / 06 / 98$ & $13 / 11 / 98$ & $17 / 06 / 00$ & $17 / 06 / 00$ & $21 / 06 / 00$ \\
& $M_{W}$ & 5.4 & 5.1 & 6.5 & 5.8 & 6.4 \\
\hline
\end{tabular}




\begin{tabular}{|c|c|c|c|c|c|c|c|}
\hline Site Name & Code & Site Class & \multicolumn{5}{|c|}{$\boldsymbol{R}_{e p i} / \boldsymbol{R}_{j b}(\mathrm{~km})$} \\
\hline Hella $^{(1)}$ & HEL & Stiff Soil & 49 & 49 & 10 & 13 & 19 \\
\hline Kaldarholt ${ }^{(1)}$ & KAL & Stiff Soil & 40 & 43 & 6 & 6 & 11 \\
\hline Reykjavik-Hus Verslunarinnar(2) & RHV & Rock & 32 & 34 & 77 & 74 & 60 \\
\hline Reykjavik-Foldaskoli ${ }^{(1)}$ & $\mathrm{RF}$ & Rock & 27 & 30 & 71 & 68 & 54 \\
\hline Reykjavik-Heidmork (Jadar) ${ }^{(1)}$ & $\mathrm{RHJ}$ & Rock & 23 & 25 & 69 & 65 & 52 \\
\hline Burfell-Hydroelectric Power Station ${ }^{(2)}$ & BHPS & Rock & 71 & 76 & 26 & 35 & 43 \\
\hline Selfoss-Hospital ${ }^{(1)}$ & $\mathrm{SH}$ & Rock & 18 & 18 & 31 & 26 & 14 \\
\hline Irafoss-Hydroelectric Power Station ${ }^{(2)}$ & IHPS & Rock & 15 & 22 & 33 & 31 & 16 \\
\hline Hveragerdi-Church ${ }^{(1)}$ & $\mathrm{HC}$ & Rock & 6 & 9 & 41 & 36 & 24 \\
\hline
\end{tabular}

Table 6. Summary of the results for the selected Icelandic earthquakes. Stiff soil and rock sites were assumed to have an average shear wave velocity in the top of $30 \mathrm{~m}$ of 490 and $960 \mathrm{~m} / \mathrm{s}$, respectively. A strike slip fault dipping at $90^{\circ}$ was assumed. The depth to the top of rupture is $5 \mathrm{~km}$. Depth to the 1,000 and $2,500 \mathrm{~m} / \mathrm{s}$ shear-wave velocity horizons are 412 and 2,000 $\mathrm{m}$, and the depth to the base of the seismogenic layer is $15 \mathrm{~km}$, [Stafford et al., 2008]. A bold number means the effect is significant at $0.1 \%$ or less using the F-test. dfS $=8, \mathrm{dfE}=4, \mathrm{dfR}=32, \mathrm{dfT}=44$

\begin{tabular}{cccccccccccccc}
\hline \multirow{2}{*}{ Period } & \multicolumn{1}{c}{ Icelandic GMPEs } & \multicolumn{2}{c}{ AB10 } & \multicolumn{2}{c}{ ADSS05 } & \multicolumn{2}{c}{ CB08 } & \multicolumn{2}{c}{ BA08 } & \multicolumn{2}{c}{ CY08 } \\
& $\boldsymbol{R}_{\boldsymbol{E}}$ & $\boldsymbol{R}_{S}$ & $\boldsymbol{R}_{\boldsymbol{E}}$ & $\boldsymbol{R}_{S}$ & $\boldsymbol{R}_{\boldsymbol{E}}$ & $\boldsymbol{R}_{S}$ & $\boldsymbol{R}_{\boldsymbol{E}}$ & $\boldsymbol{R}_{S}$ & $\boldsymbol{R}_{\boldsymbol{E}}$ & $\boldsymbol{R}_{S}$ & $\boldsymbol{R}_{\boldsymbol{E}}$ & $\boldsymbol{R}_{S}$ \\
\hline $\mathrm{PGA}$ & 2.4 & $\mathbf{3 . 1}$ & $\mathbf{1 4 . 9}$ & $\mathbf{1 2 . 9}$ & $\mathbf{1 7 . 8}$ & 7.4 & $\mathbf{2 1 . 6}$ & 9.5 & $\mathbf{1 1 . 6}$ & $\mathbf{1 3 . 5}$ & $\mathbf{1 6 . 0}$ & $\mathbf{8 . 3}$ \\
$\mathrm{Sa}(0.2 \mathrm{~s})$ & 2.1 & $\mathbf{3 . 5}$ & $\mathbf{1 1 . 4}$ & $\mathbf{1 3 . 2}$ & $\mathbf{1 0 . 8}$ & 6.7 & $\mathbf{1 8 . 9}$ & $\mathbf{1 4 . 8}$ & 9.0 & $\mathbf{1 4 . 8}$ & $\mathbf{1 0 . 9}$ & $\mathbf{8 . 2}$ \\
$\mathrm{Sa}(0.5 \mathrm{~s})$ & $\mathbf{4 . 0}$ & $\mathbf{4 . 0}$ & $\mathbf{1 5 . 9}$ & $\mathbf{8 . 0}$ & $\mathbf{1 2 . 9}$ & 4.3 & $\mathbf{2 5 . 5}$ & 7.0 & $\mathbf{1 1 . 1}$ & $\mathbf{1 0 . 2}$ & $\mathbf{3 0 . 8}$ & $\mathbf{5 . 4}$ \\
$\mathrm{Sa}(1.0 \mathrm{~s})$ & $\mathbf{5 . 4}$ & 2.3 & 5.6 & 3.2 & 7.6 & 2.1 & $\mathbf{1 4 . 0}$ & 3.0 & 9.3 & 5.9 & $\mathbf{1 0 . 2}$ & 2.3 \\
$\mathrm{Sa}(2.0 \mathrm{~s})$ & $\mathbf{4 . 4}$ & 2.1 & $\mathbf{9 . 6}$ & 3.6 & $\mathbf{1 2 . 0}$ & 2.3 & $\mathbf{2 5 . 9}$ & 3.8 & $\mathbf{1 6 . 8}$ & 5.9 & $\mathbf{1 5 . 8}$ & 3.1 \\
\hline
\end{tabular}


Table 7. The number of strong ground motion records, earthquakes and stations and number of negative residuals of RS and RE from 1000 simulated datasets.

\begin{tabular}{crr}
\hline \multirow{2}{*}{ Number of strong motion records } & \multicolumn{2}{c}{ Test } \\
\cline { 2 - 3 } & $\mathbf{1}$ & $\mathbf{2}$ \\
\hline 25 (5 eqs and 5 sts) & 313 & 254 \\
100 (10 eqs and 10 sts) & 120 & 131 \\
225 (15 eqs and 15 sts) & 59 & 71 \\
400 (20 eqs and 20 sts) & 36 & 45 \\
625 (25 eqs and 25 sts) & 17 & 30 \\
$900(30$ eqs and 30 sts) & 8 & 22 \\
1225 (35 eqs and 35 sts) & 7 & 12 \\
\hline
\end{tabular}

Table 8 . Assumed components of variability

\begin{tabular}{ccccc}
\hline Test & $\sigma_{\text {event }}$ & $\sigma_{\text {station }}$ & $\sigma_{\text {record }}$ & $\sigma_{\text {total }}$ \\
\hline $\mathbf{1}$ & 0.0723 & 0.1198 & 0.1640 & $\mathbf{0 . 2 1 5 6}$ \\
$\mathbf{2}$ & 0.1465 & 0.2184 & 0.1345 & $\mathbf{0 . 2 9 5 4}$ \\
\hline
\end{tabular}


Table 9. Average residual (in bold) for each individual station based on the AB10 GMPEs with the standard error of the mean, $\sigma_{\mu}$ (in italics). Red letters indicate that the Student's t test rejects the null hypothesis at the 5\% level of significance.

\begin{tabular}{|c|c|c|c|c|c|c|c|c|c|}
\hline $\mathrm{T}(\mathrm{s})$ & HEL & KAL & RHV & RF & RHJ & BHPS & SH & IHPS & $\mathrm{HC}$ \\
\hline 0.0 & $0.037 \pm 0.057$ & $0.195 \pm 0.049$ & $-0.396 \pm 0.122$ & $-0.463 \pm 0.122$ & $-0.452 \pm 0.130$ & $-0.432+0111$ & $0200+0105$ & $5-0560+0135$ & $-0.074 \pm 0.105$ \\
\hline 0.2 & $-\mathbf{0 . 0 3 1} \pm 0.053$ & $0.291 \pm 0.070$ & $-0.410 \pm 0.141$ & $-0.494 \pm 0.126$ & $-0.568 \pm 0.134$ & $-0.491 \pm 0.124$ & $-0.229 \pm 0.124$ & $-0.610 \pm 0.129$ & $-\mathbf{0 . 1 3 6} \pm 0.081$ \\
\hline 0.5 & $-0.166 \pm 0.077$ & $0.033 \pm 0.108$ & $-0.409 \pm 0.105$ & $-0.428 \pm 0.086$ & $-0.157 \pm 0.112$ & $-0.480 \pm 0.061$ & $-0.140 \pm 0.104$ & $-0.341 \pm 0.091$ & $-0.149 \pm 0.069$ \\
\hline 1.0 & $-0.179 \pm 0.048$ & $0.029 \pm 0.059$ & $-0.173 \pm 0.100$ & $-0.174 \pm 0.083$ & $0.105 \pm 0.129$ & $-0.300 \pm 0.030$ & $0.032 \pm 0.062$ & $-\mathbf{0 . 0 6 5} \pm 0.092$ & $0.089 \pm 0.110$ \\
\hline 2.0 & $-0.179 \pm 0.067$ & $0.076 \pm 0.029$ & $-0.092 \pm 0.067$ & $-0.119 \pm 0.046$ & $-0.016 \pm 0.048$ & $-\mathbf{0 . 0 3 2} \pm 0.062$ & $0.136 \pm 0.077$ & $\mathbf{0 . 0 0 3} \pm 0.148$ & $0.166 \pm 0.085$ \\
\hline
\end{tabular}

Table 10. Single-station sigma (in bold) for each individual station based on AB10 with the standard error of the standard deviation, $\sigma_{\sigma}$ (in italics)

\begin{tabular}{|c|c|c|c|c|c|c|c|c|c|c|}
\hline $\mathrm{T}(\mathrm{s})$ & HEL & KAL & RHV & RF & RHJ & BHPS & SH & IHPS & HC & $\begin{array}{c}\text { Multi-station } \\
\text { sigma }\end{array}$ \\
\hline 0.0 & $0.141 \pm 0.041$ & $0.109 \pm 0.03$ & $0.274 \pm 0.08$ & $70.300 \pm 0$. & $0.319 \pm 0.0$ & $0.249 \pm 0.0$ & $0.257 \pm 0$ & $0.302 \pm 0.0$ & $0.235 \pm 0.074$ & 0.2793 \\
\hline 0.2 & $0.129 \pm 0.037$ & $0.156 \pm 0.04$ & $0.316 \pm 0.10$ & $0.308 \pm 0$. & $0.328 \pm 0.0$ & $0.277 \pm 0.0$ & $0.304 \pm 0$ & $0.288 \pm 0.0$ & $0.182 \pm 0.058$ & 0.3021 \\
\hline 0.5 & $0.188 \pm 0.054$ & $0.241 \pm 0.0$ & $0.235 \pm 0.07$ & $40.210 \pm 0$. & $0.275 \pm 0.0$ & $0.136 \pm 0.0$ & $0.254 \pm 0$ & $0.204 \pm 0.0$ & $0.154 \pm 0.049$ & 0.3290 \\
\hline 1.0 & $0.119 \pm 0.034$ & $0.133 \pm 0.04$ & $0.223 \pm 0.0$ & $0.202 \pm 0$. & $0.316 \pm 0.0$ & $0.067 \pm 0.0$ & $0.152 \pm 0$. & $0.206 \pm 0.0$ & $0.246 \pm 0.078$ & 0.3253 \\
\hline 2.0 & $0.165 \pm 0.048$ & $0.064 \pm 0.02$ & $0.150 \pm 0.04$ & $70.112 \pm 0$. & $0.119 \pm 0.0$ & $0.138 \pm 0.0$ & $0.189 \pm 0$. & $0.331 \pm 0.1$ & $0.191 \pm 0.060$ & 0.3284 \\
\hline
\end{tabular}



Table 11. Summary of standard deviation of residuals using the local and AB10 equations

\begin{tabular}{c|c|c|c|c}
\hline \multirow{2}{*}{$\mathbf{T}$} & Multi-station sigma & Single-station sigma & \multicolumn{2}{|c}{$\Delta$ difference (\%) } \\
\cline { 2 - 5 }$(\mathbf{s})$ & $\mathbf{A B 1 0}$ & $\mathbf{A B 1 0}$ & $\mathbf{A B 1 0}$ & $\begin{array}{c}\text { Atkinson } \\
{[\mathbf{2 0 0 6}]}\end{array}$ \\
\hline $\mathbf{0 . 0}$ & 0.2793 & 0.2436 & $-13 \%$ & $-15 \%$ \\
$\mathbf{0 . 2}$ & 0.3021 & 0.2552 & $-16 \%$ & - \\
$\mathbf{0 . 3}$ & - & - & - & $-10 \%$ \\
$\mathbf{0 . 5}$ & 0.3290 & 0.2125 & $-35 \%$ & - \\
$\mathbf{1 . 0}$ & 0.3253 & 0.1857 & $-43 \%$ & $-8 \%$ \\
$\mathbf{2 . 0}$ & 0.3284 & 0.1607 & $-51 \%$ & - \\
\hline
\end{tabular}

Table 12. Gutenberg-Richter a- and b- parameters for the SISZ with completeness intervals for different magnitude classes

\begin{tabular}{ccccc}
\hline \multirow{2}{*}{$\boldsymbol{b}$} & $\boldsymbol{a}$ & \multicolumn{2}{c}{ Completeness Intervals } \\
\cline { 3 - 5 } & & $\mathbf{M w} \geq \mathbf{4 . 0 0}$ & $\mathbf{M w} \geq \mathbf{5 . 0 0}$ & $\mathbf{M w} \geq \mathbf{6 . 0 0}$ \\
\hline 0.52 & 2.01 & 1940 & 1930 & 1896 \\
\hline
\end{tabular}




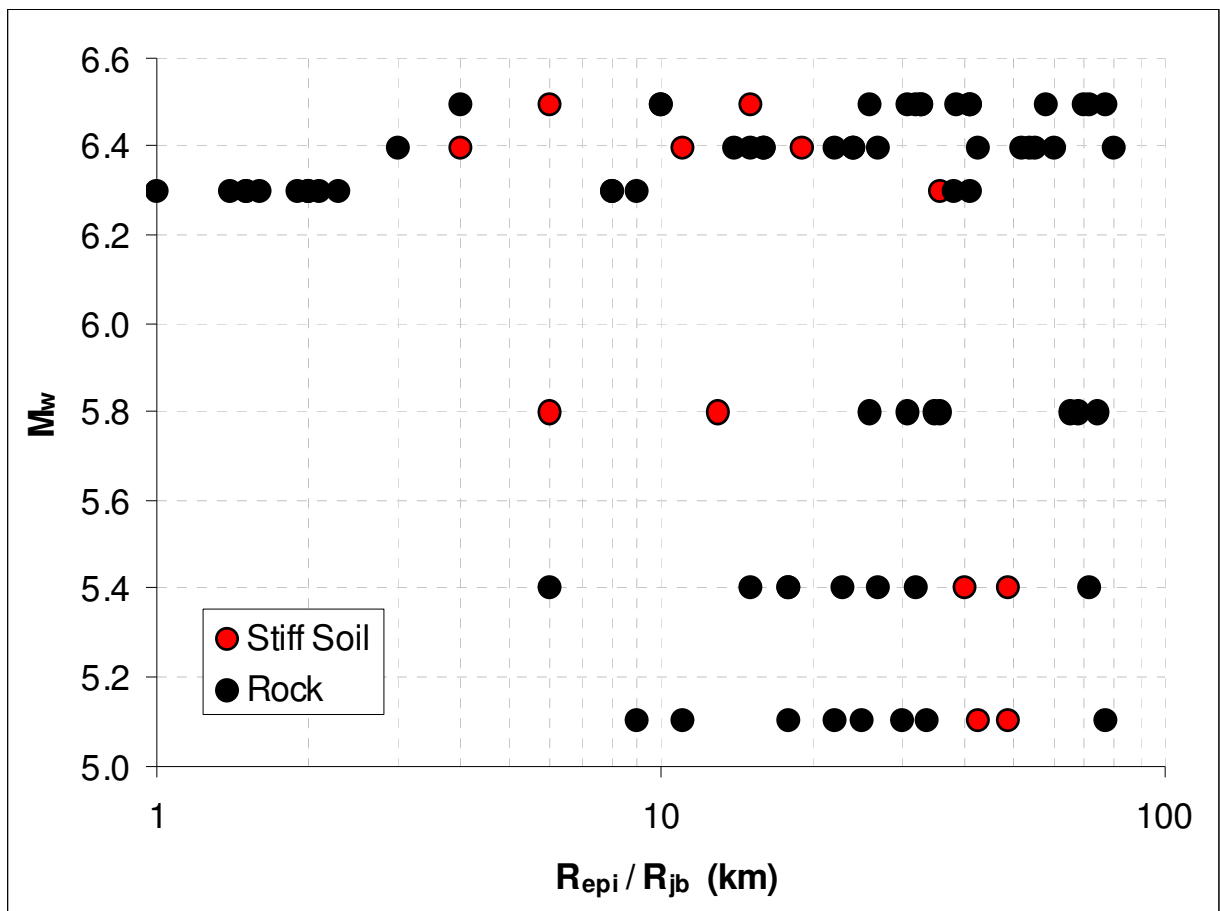

Figure 1. Moment magnitude versus epicentral/ Joyner-Boore distance of data used to derive Icelandic GMPEs. 


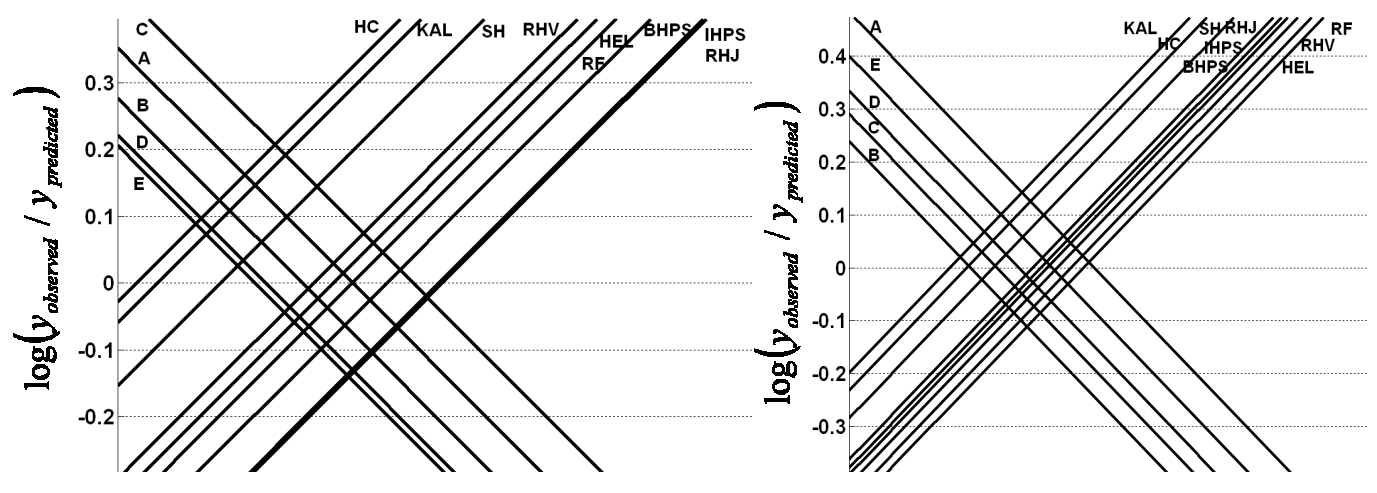

Figure 2. Two-way-fit plots for Icelandic GMPE at SA (0.2s) (Left) and SA (2s) (Right) 

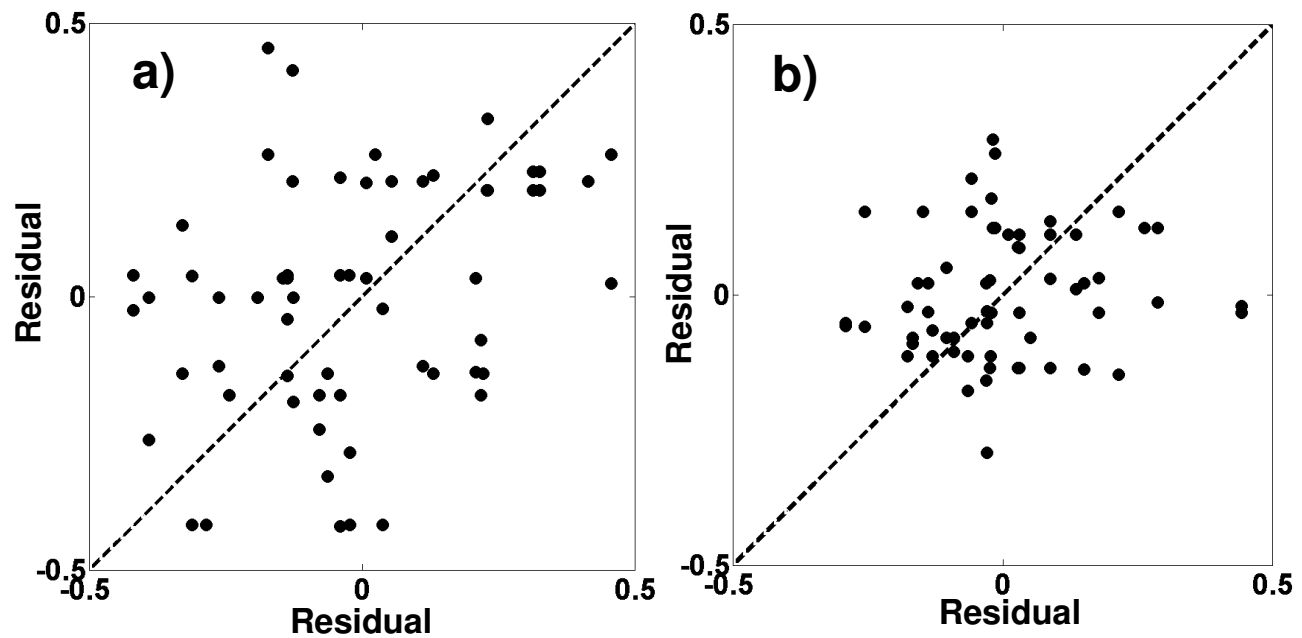

Figure 3. Residual-residual plots for SA at $0.2 \mathrm{~s}$ (a) and SA at $2 \mathrm{~s}$ (b) for randomly combined stations as proposed by Lee et al. (1998) with correlation coefficients of 0.32 and 0.11 , respectively. The residuals are corrected for the inter-event errors for stations with more than one record. 


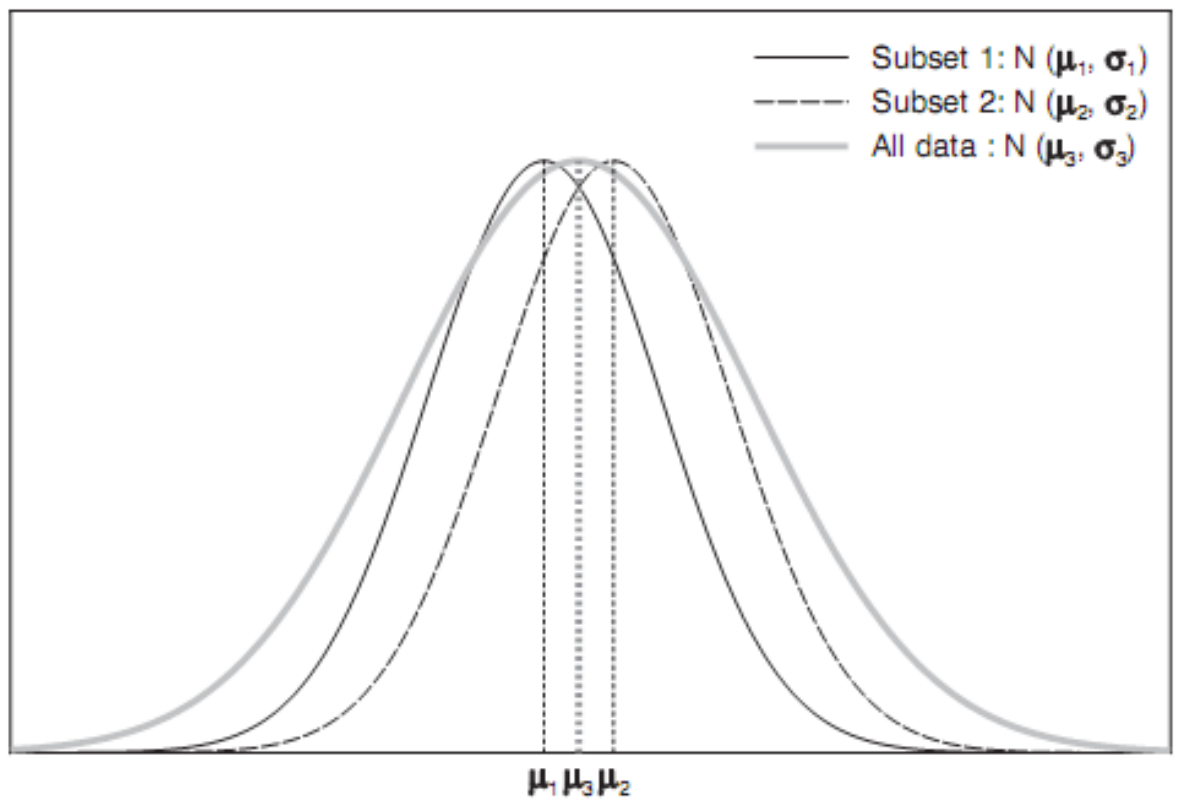

Figure 4. Schematic illustration of the effect of mixing spatial and temporal variability in GMPEs for traditional PSHA (Strasser, et al., 2009). 


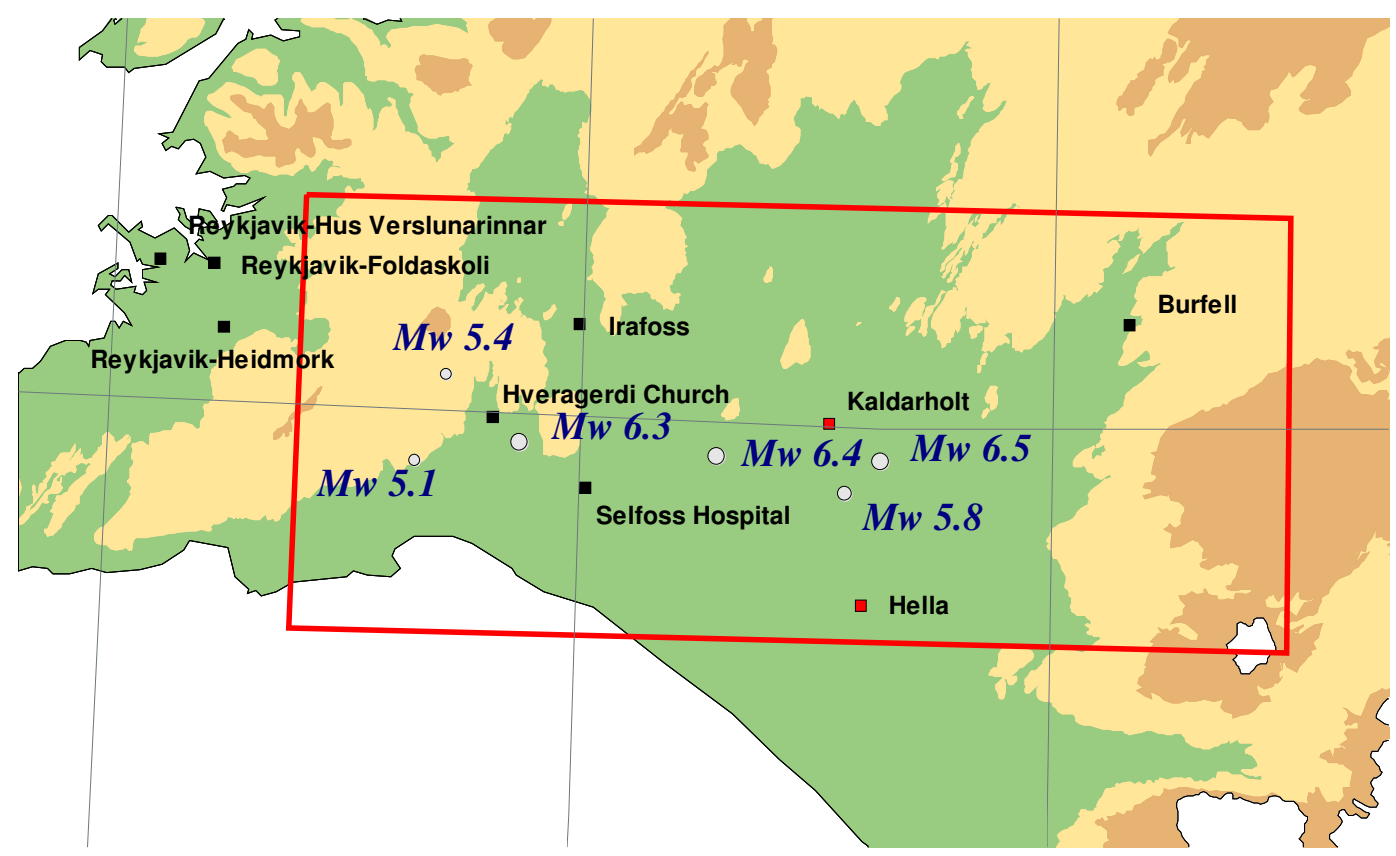

Figure 5. Map showing nine stations (black and red squares for rock and shallow alluvium stations, respectively), six earthquakes (white circles), and SISZ zone (large red square) considered in this study 
PGA

$\mathbf{T}=\mathbf{1 . 0 \mathrm { s }}$
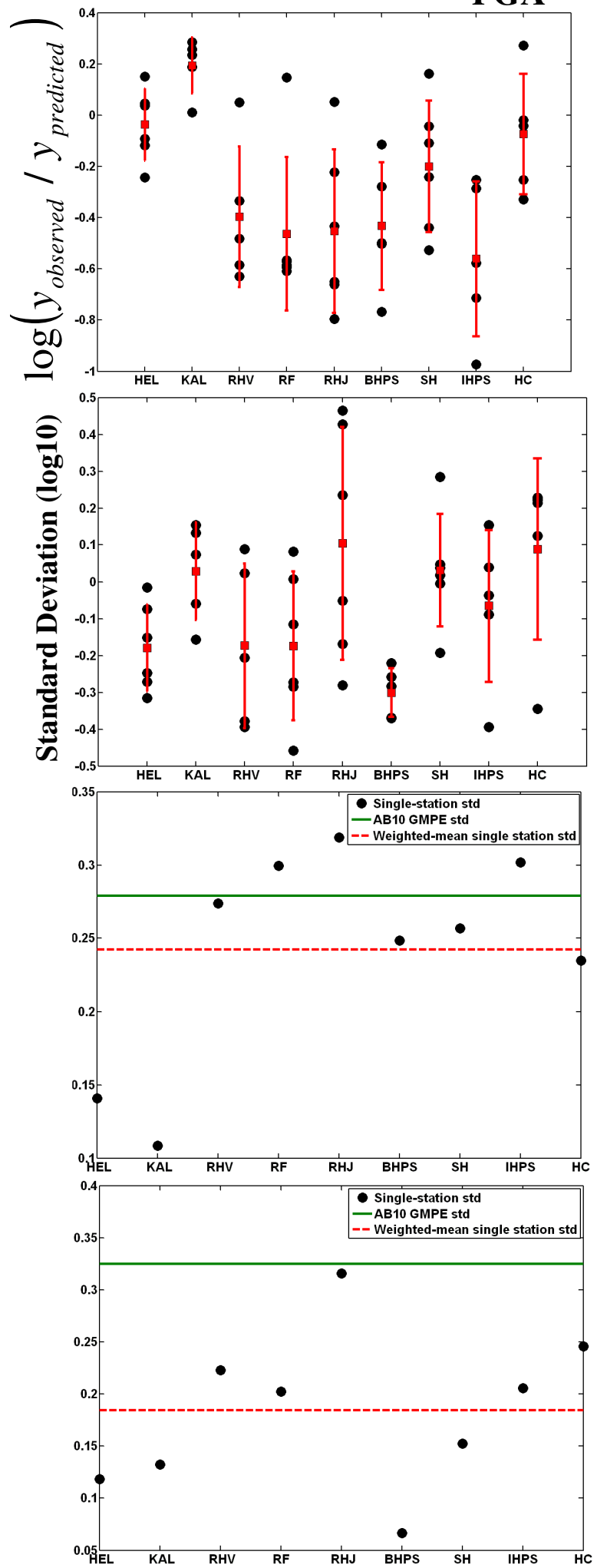

Figure 6. Residuals (black circle) and average residuals (red square) with sigma (red line) (Upper) and the standard deviation of the residuals (Lower) for each station for PGA (Left) and ( $\mathrm{T}=1.0 \mathrm{~s}$ ) (Right) based on the AB10 GMPE. 


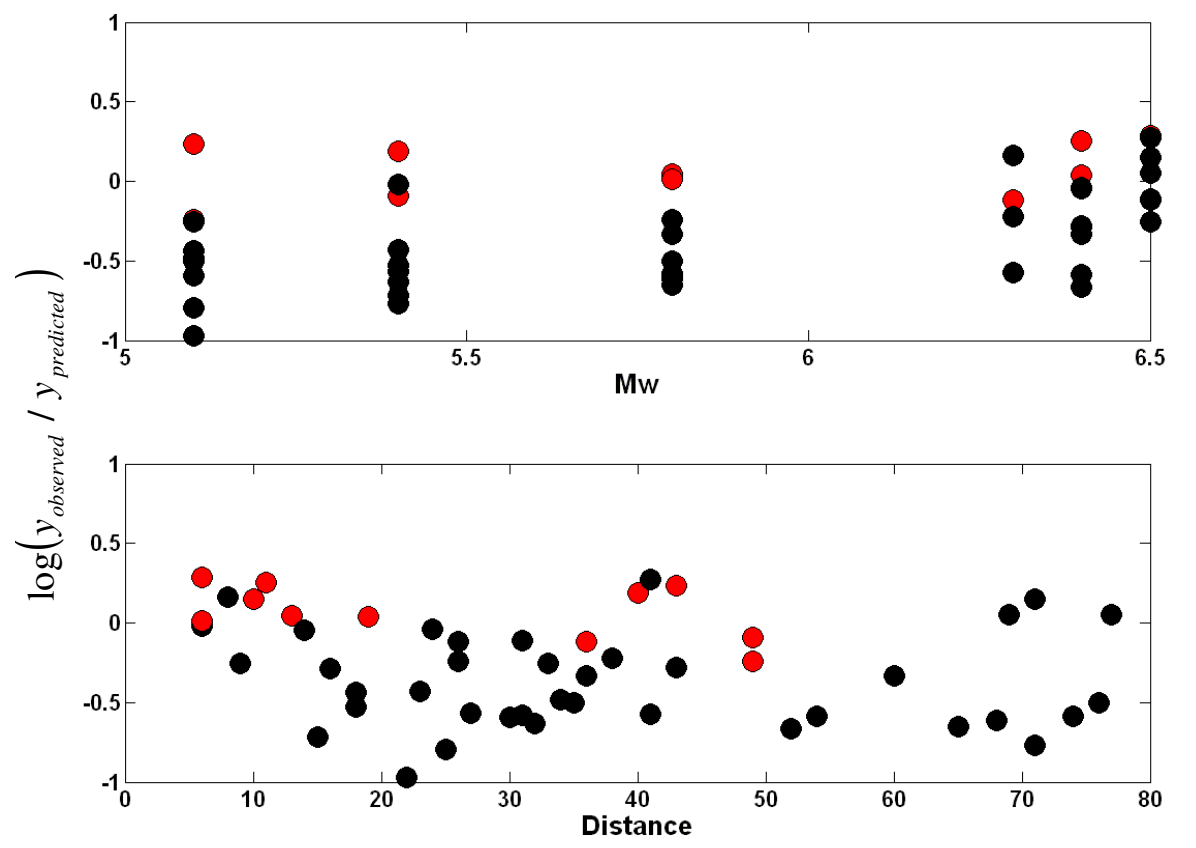

Figure 7. Geometric-mean PGA residuals against moment magnitude and distance using soil coefficient of $\mathrm{AB} 10$ (45 records from 5 earthquakes and 9 stations with 4 additional records form Mw 6.3, Olfus 2008 at same stations) 


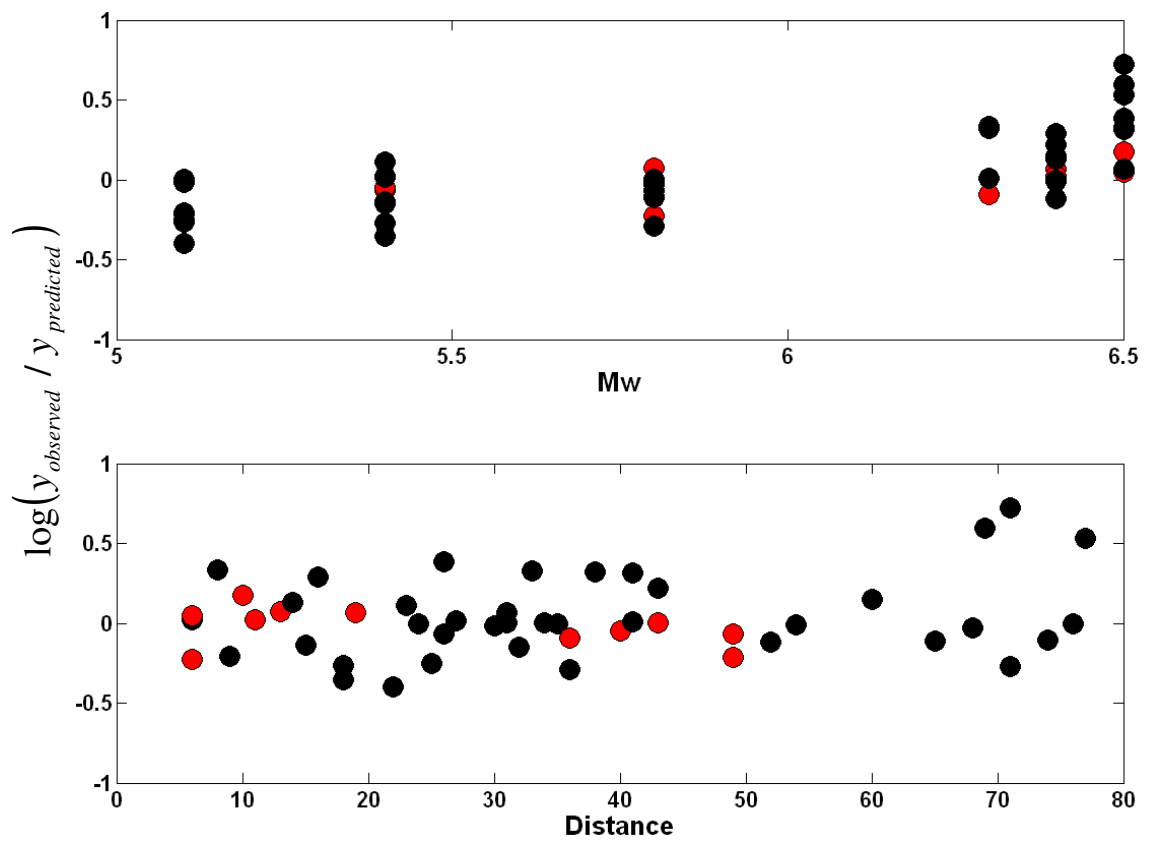

Figure 8. Geometric-mean PGA residuals against moment magnitude and distance using station coefficient of $\mathrm{AB} 10$ (45 records from 5 earthquakes and 9 stations with 4 additional records form Mw 6.3, Olfus 2008 at same stations)

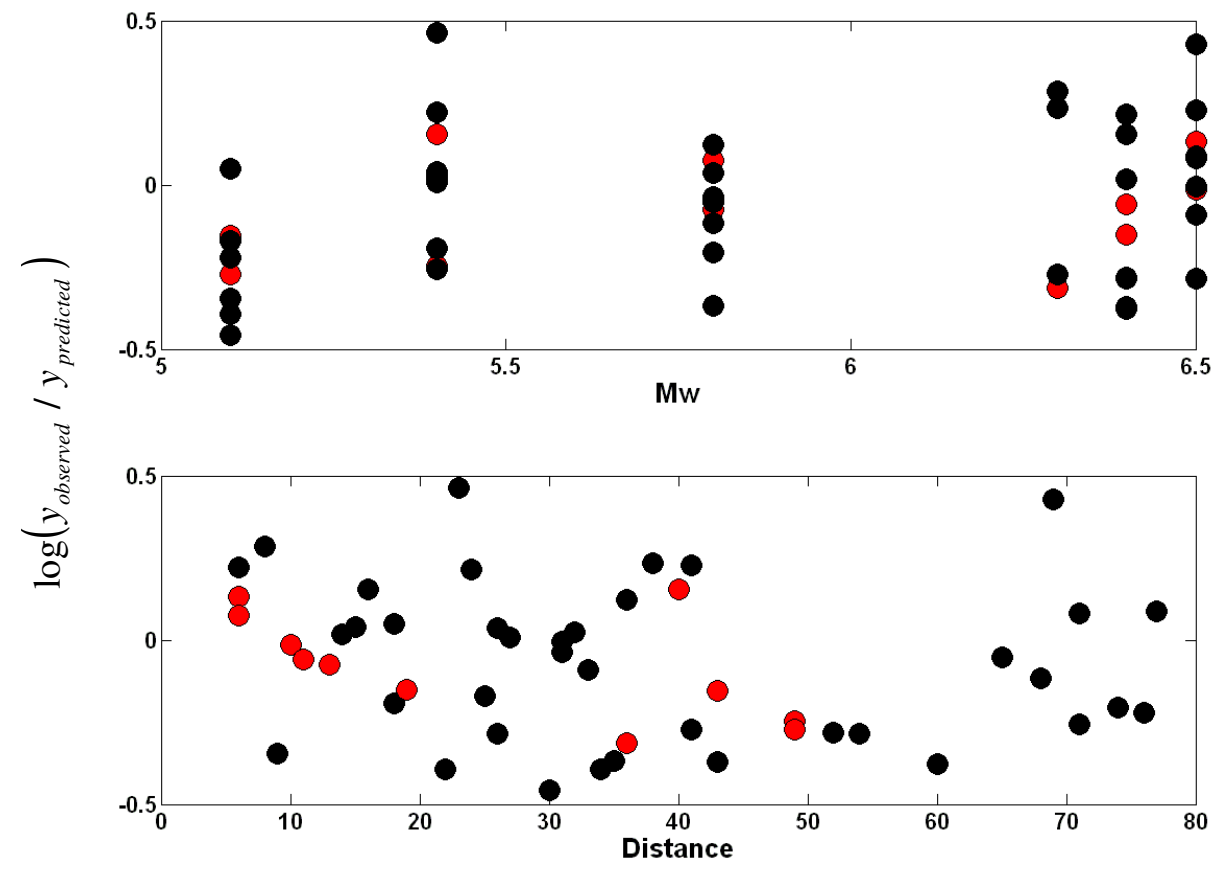

Figure 9. Geometric-mean SA $(\mathrm{T}=1.0 \mathrm{~s})$ residuals against moment magnitude and distance using soil coefficient of AB10 (45 records from 5 earthquakes and 9 stations with 4 additional records form Mw 6.3, Olfus 2008 at same stations) 

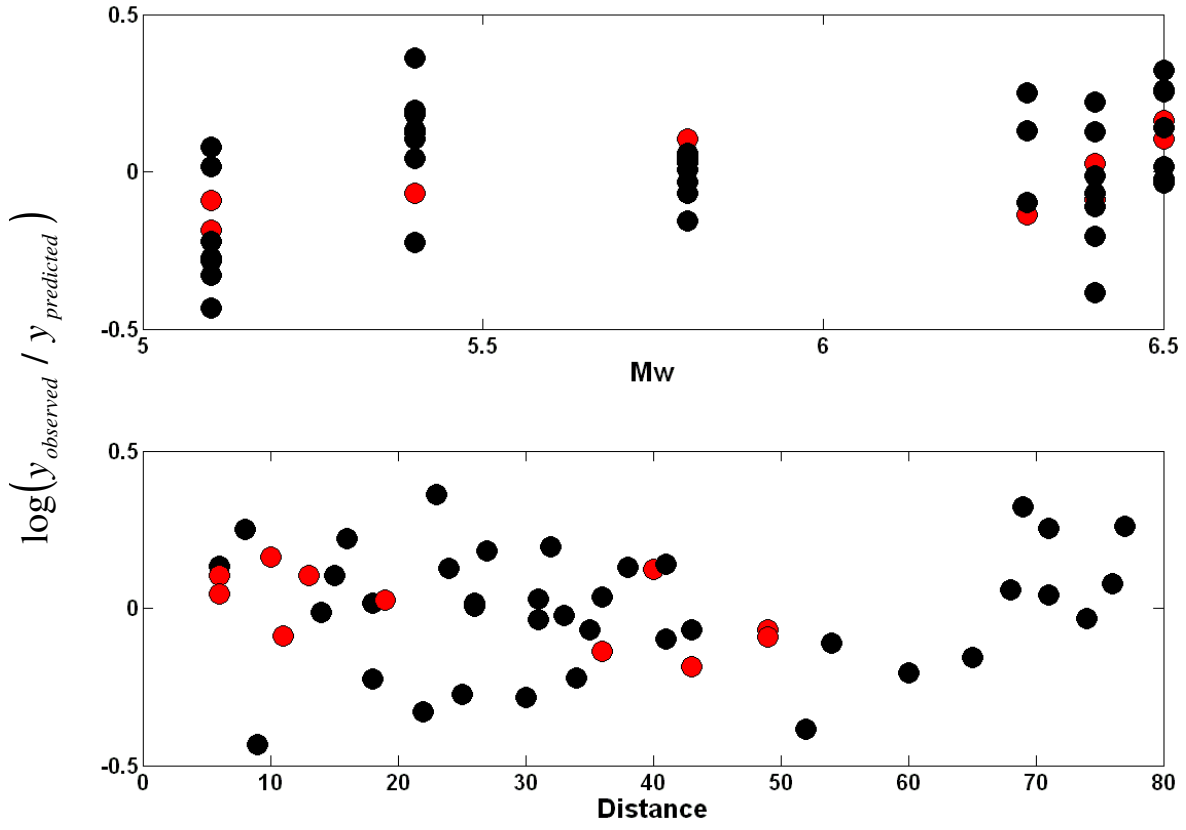

Figure 10. Geometric-mean SA $(T=1.0 \mathrm{~s})$ residuals against moment magnitude and distance using station coefficient of $\mathrm{AB} 10$ (45 records from 5 earthquakes and 9 stations with 4 additional records form Mw 6.3, Olfus 2008 at same stations)

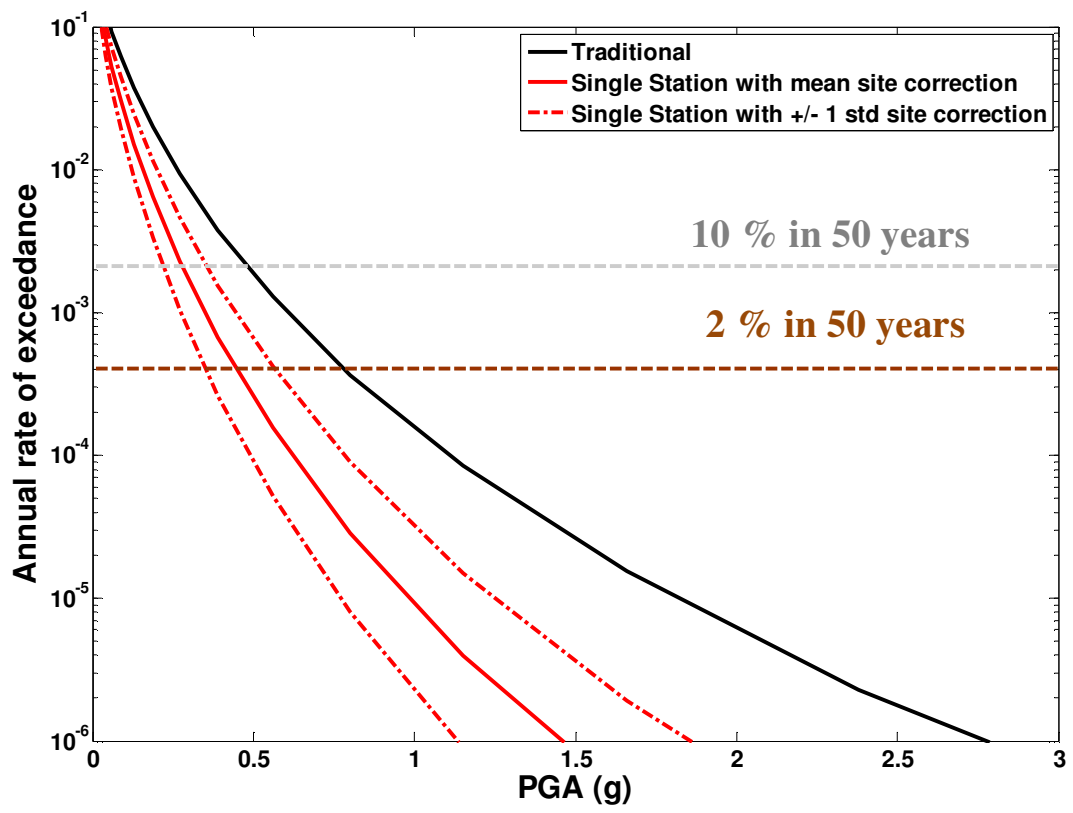

Figure 11. Comparison of hazard curves at Selfoss hospital using traditional and non-ergodic assumptions with mean and +/- 1 standard deviation site correction 


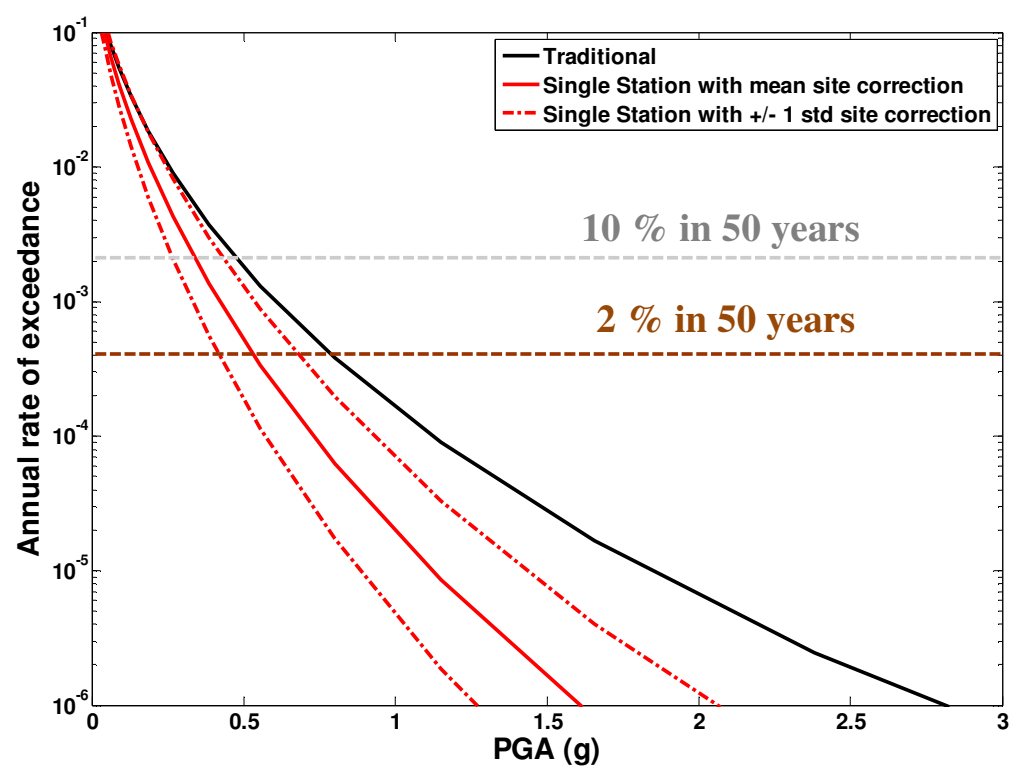

Figure 12. Comparison of hazard curves at Hveragerdi church using traditional and non-ergodic assumptions with mean and $+/-1$ standard deviation site correction

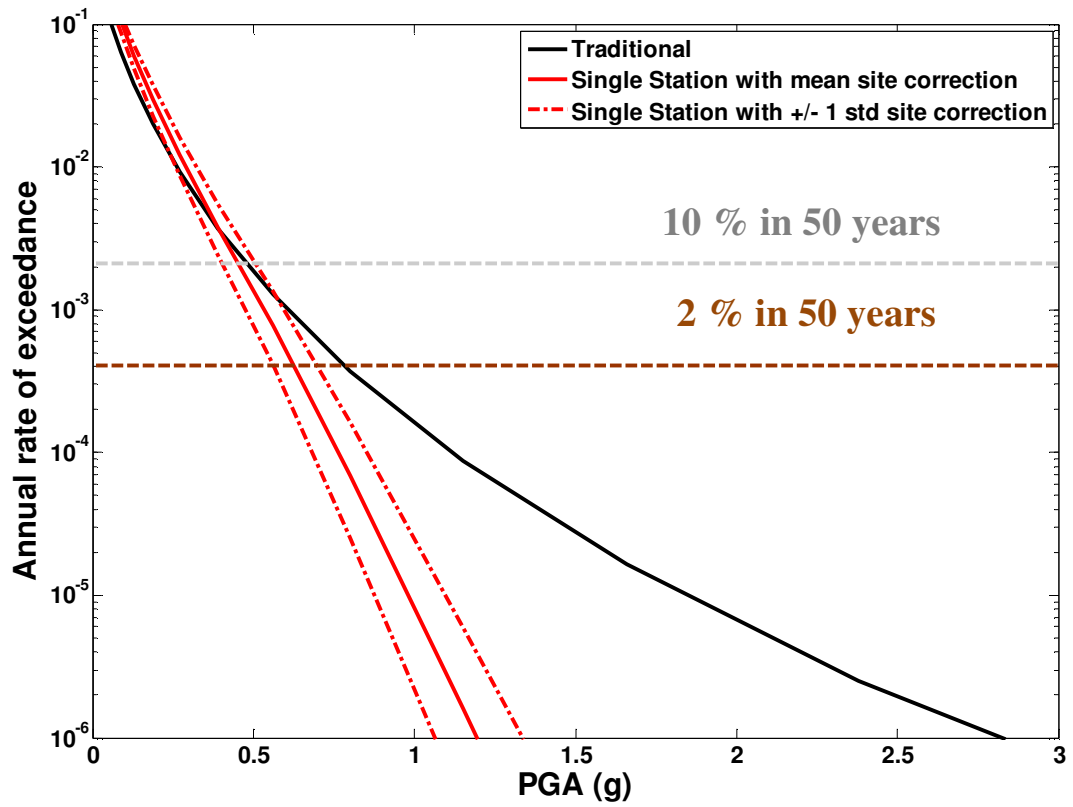

Figure 13. Comparison of hazard curves at Kaldarholt using traditional and non-ergodic assumptions with mean and +/- 1 standard deviation site correction 